Papers and Proceedings of the Royal Society of Tasmania, Volume 116, 1982

(ms. received 5.1.1982)

OBSERVATIONS ON SOME TASMANIAN FISHES: PART XXVIII

by E.O.G. Scott

Launceston

(with six tables, nine text-figures and four plates)

ABSTRACT

SCOTT, E.O.G., 1982 ( 31 viii): Observations on some Tasmanian fishes: Part XXVIII. Pap. Proc. R. Soc. Tasm., 116: 181-217. https://doi .org/10.26749/rstpp.116.181 ISSN 0080-4703. Queen Victoria Museum and Art Gallery, Launceston Tasmania.

OPHICHTHYIDAE. Ophisurus serpens Linné, 1758: large scale stranding on Flinders Island; specimens described, compared with earlier material. NOMEIDAE. Cubiceps caeruleus Regan, 1914: first Tasmanian record; general account; ventral rays. REGALECIDAE. Regalecus pacificus Haast, 1878: general account, with photographs, of two recent local strandings; color pattern. CARANGIDAE. Trachurus novaezelandiae Richardson, 1843: additional records; comparison with first Tasmanian specimen, reported as T. meculZochi Nichols, 1920. SCOMBRIDAE. Gasterochisma melampus Richardson, 1845: specimen from western Tasmania (Earthwatch); comparison with earlier material; height of dorsal and anal finlets functions of dorsal and ventral body profiles. BOVICHTHYIDAE. Pseudaphritis bursinus (Cuvier, 1830): considered senior synonym of P. urvillii; detailed study with a critical review of published accounts of species; differential growth; length of ventral rays a function of height of body.

\title{
INTRODUCTION
}

This paper follows the general plan of others in the series. Linear measurements are given throughout in millimetres, unless otherwise specified, the name of the unit commonly being omitted. The symbols Ls, Lt, TLs, TLt denote standard length, total length, thousandths (permillages) of standard length, thousandths of total length, respectively. Registration numbers denoted by Q.V.M. are those of the Queen Victoria Museum and Art Gallery, Launceston. Certain other conventions are noted in earlier contributions.

Records of certain quantitative data (general morphometrics, including equations) not incorporated in the text are deposited with the Royal Society of Tasmania, Hobart, with a duplicate copy in the Queen Victoria Museum and Art Gallery, Launceston, Tasmania. The omission of such data from the published text is indicated at the relevant point by the notation (Appendix [number]).

\section{SYSTEMATIC ZOOLOGY}

\section{Family OPHICHTHYIDAE}

The snake eels or serpent eels, Ophichthyidae (frequently rendered Ophichthidae; in early texts, e.g. Günther (1880), subsumed in the wide Muraenidae) are distinguished at sight from the other groups of common large anguilliform fishes found in our waters - the typical eels Anguillidae, morays Muraenidae, congers Congridae (in most Australian texts Leptocephalidae), worm eels Xenocongridae (in most Australian texts Echelidae) - in having the dorsal and anal fins (where present, as is modal) ending in front of the tail tip, which projects as a stiff usually blunt naked process. They differ further from Muraenidae and Xenocongridae in being provided (in the great majority of cases) with pectoral fins, from the Anguillidae in lacking scales, and from the Congridae in having caniniform teeth. Of the eleven members of the family recorded from Australia (Munro 1957a), two only are known to occur outside Queensland, Northern Territory and Western 
Australia, one, ophisums serpens (Linne, 1758) being found in Tasmania, New South Wales and Western Australia.

Genus OPHISURUS Lacépède, 1880

Ophisurus Lacépède, 1880, P. 195. Type-species, Muraena serpens Linne.

Ophisurus: Mcculloch, 1929, p.68 (generic synonymy).

ophisurus serpens (Linné 1758)

Muraena serpens Linné, 1758, p.244 (ed. 12, 1776, p.425: based on Artedi, gen.24, syn.41).

Type locality: southern European seas.

Ophisurus semens?: Ogilby, $1897 \mathrm{a}, \mathrm{p} .85$.

Ophisums semens: Macleay, 1882b, p.273: Ogilby, 1879b, p.159, footnote: McCulloch, 1921, p.35, pl.23, fig. 85a, and 1929, 5(1), p.68: Lord, 1923, p.64, and 1927, p.13: Lord \&

Scott, 1924, pp.8,37: Munro, 1957a, p.47, fig.330: Scott, 1963, p.15, fig.3, and 1980, p. 105 .

Pophisurus serpens: Schlegel, 1850, p.264, pl.115, 1 .

?Leptorhyncus capensis Smith, 1840, p1.6. Type locality: Table Bay, South Africa.

?Ophisurus macrorhynchos Bleeker, 1853, pp.9,28. Type locality: Kaminoseki, Japan.

?ophisurus novaezeZandiae Hector, 1870, p.34, p1.3. Type locality: Poverty Bay, New

Zealand.

Leptognathus novaezelandiae: Whitley, $1964, \mathrm{p} .36$.

Occurrence in Tasmania

The early history in this State of this species has been reviewed in Part XI (1963). Lord \& Scott (1924: 37) stated that they knew of no local reports other than the original one by Ogilby (1897a,b). A confirmatory record, based on a specimen, $L t$ 1144, found in a lagoon near the mouth of the George River, east coast, was given in Part XI (1963), and some observations on an example, $L t 601$, hooked near the mouth of the same river, were presented in Part XXVI (1980).

Specific status

As pointed out earlier, the question as to whether the Tasmanian eel is conspecific with the European 0 . sempens or merely closely allied to it would appear to remain in doubt pending a direct comparison of specimens from the two hemispheres. Few precise observations on Australian material have hitherto been available; accordingly a general account of the first specimen received by the Museum was given, together with a figure illustrating the dentition. On receipt of additional examples the opportunity is here taken to record further morphometric and other specifications.

\section{Large scale stranding}

In October 1981 the Queen Victoria Museum, Launceston received from Mr K.W. Grace two examples of this species secured in unusual circumstances at Cameron Inlet on the east coast of Flinders Island, Bass Strait, a little south of the 40th parallel. Police

Sergeant H.U. Schindler, Whitemark, who has been good enough to supply some information on the occurrence here noted, informs us that this body of water, about $3 \mathrm{~km}$ in length from its northern tip, adjoining the sea, to its more iniand southern tip, and with a maximum width of $2-3 \mathrm{~km}$, though designated an inlet is essentially a coastal lagoon with a facultative access to the sea. Though at one time opened regularly to the sea by the Rivers and Water Supply Commission, using a bulldozer to make a channel through the sand, it has remained landlocked for the past seven or eight years. Recently a spontaneous break-through occurred, and the lagoon, reduced in area by about half, became tidal. The depth of the area still under water was reduced to about two-thirds of a metre. In those parts where the water persisted - with an extensive growth of weeds and containing much evil-smelling decayed organic material brought in by numerous drains (the area being an abandoned Soldier Settlement) - the eels remained in general in a lively condition, hiding under weeds and when disturbed retreating to their burrows in the sand (the naked caudal end of the body of the ophichthyids is commonly held to act as a burrowing organ). However, some 
hundreds were stranded high and dry, many showing evidence of damage resulting from exposure to the hot sun. Mr Schindler states the great majority were about three-quarters of a metre in length, with a few exceeding a metre. No stranded fish of any other species were observed. The two specimens forwarded to the Museum, Lt 904, $1031 \mathrm{~mm}$ (Q.V.M. Reg. No. 1981/5/57) are here made the subject of some direct observations and of comparison with other Tasmanian examples from the east coast.

\section{Dimensions}

Specimens are recorded in order of increasing total length, (601, 904, 1 031, 1 144) all dimensions being thousandths of total length (in ophthichthyids effectively standard length). Length to origin of dorsal 104, 102, 102, 133, to termination 975, 989, 986, 987. Length to origin of anal $356,350,368,407$, to termination $983,989,988,987$. Length to vent (mi ddle) $344,345,360,363$. Length to origin of pectoral $71.5,68.6,75.7$, 一, length of fin $14.5,18.3,17.7,17.0$. Head $68.2,66.4,73.7,76.0$ Snout 16.8, 16.6, 18.6, 20.0. Eye 6.7, 5.5, 6.7,6.6. Interorbital $6.5,6.0,7.1,8.0$. Depth (in parentheses width) at front of eye $9.7(7.0), 9.3(7.9), 8.7(8.7), 12(9.6)$, at back of eye $11.3(8.3)$, $10.0(9.4), 13.6(11.6), 16(14)$; at gill slit $20.0(15.8), 16.9(16.6), 19.5(17.6),-(-)$, at dorsa1 origin - $-(19.9(18.0), 21.3(20.4),-(-)$, at vent $15.1(16.3), 20.5(20.0), 22.3$ $(22.5), 17(17)$; maximum, head $21.6(15.8), 17.1(17.7), 20.3(18.0),-(-)$, body $16.6(16.6)$, $21.6(20.7), 22.3(22.8),-(-)$.

\section{Proportions}

Values for the five proportions given in the Handbook (Munro 1957a:47) - these shown below in parentheses - for our four examples, in increasing order of total length are as follows. Mouth cleft in head, 2.1, 2.0, 2.1, 1.9(2.0): the large mouth cleft trenchantly distinguishes this from other Australian ophichthyids in which it is $\$ 3$ in head. Eye in snout $2.5,3.0,2.8,3.0(2.9)$. Head in trunk $3.8,4.2,3.9,3.8(3.6-5.2)$. Head in tail $9.6,9.9,8.7,8.4(7.1)$. Pectoral in head, 4.7, 3.6, 4.8, - (6). Other proportions of interest: eye in interorbital 1.2, 1.2, 1.1, 1.0: depth at front of eye in length of head $7.0,7.1,8.4,6.3$; at back of eye $6.0,6.7,5.4,4.8$; at gill slit $3.4,3.9,3.8$, 一; at vent $4.5,3.2,3.0,4.5$; maximum $4.4,3.1,3.30$, - ;ength to dorsal origin in total length $9.62,9.83,9.83,7.52$ : length to anal origin in total length $2.81,2.95,2.72$, 2.46 .

\section{Dentition}

The taxonomic importance of the dentition in ophichthyids has been demonstrated by Schultz (1953). This species presents a pattern of clustered premaxillary, uniserial maxillary, dentary and vomerine sets. Tolerably detailed accounts of the teeth have been given for the 1963 and 1980 individuals. The present specimens conform to the general pattern described earlier, but exhibit some individual variation. Dentary: anterior teeth in smaller fish 2 on right, 1 on left; in larger fish 2 on left, 1 on right level with first left, all large; median line of posterior hidden by fleshy lateral folds. Premaxillary: smaller, 1 small median, followed by 2 lateral largish, opposite one another; larger, 2 large on left, one large on right opposite hinder left, closely followed by 2 very slender, fine. Maxillary: usual long line of about 40 in each jaw. Vomerine: smaller, anterior spaced teeth 7 , first not much smaller than second, thereafter increasing slightly in size (in both fish followed by usual hidden line of about a dozen small closely set).

\section{Coloration}

While exhibiting the characteristic bicolor pattern, fully specified for the earlier material, the present specimens show some individual variation, both relative to the east coast specimens and between themselves. Smaller example: dorsal and upper lateral surfaces greyish, faintly yellowish; lower half of side somewhat more yellowish (the two regions thus both lighter and less strongly contrasted than in the other individuals); ventral surface whitish behind vent, silvery in front of it. Larger example: back and side above lateral line rather dark brownish olivaceous; rest of side lighter, more sharply demarcated than in smaller example; in the anterior three-tenths of the trunk the lighter area, largely becoming whitish, sloping upward and forward to reach within about 
one-fifth of height of fish from dorsal profile; ventral surface of trunk silvery, of tail white. Vertical fins, wholly withdrawn into grooves, appear as black or blackish 1 ines, representing a narrow marginal band, the remainder of the fin, its maximum height subequal to eye, being translucent or pale greyish.

Lateral line

This consists of small simple pores; in the smaller example, in which they are more evident, 71 to vent +135 , ceasing about as far in advance of anal termination as 1 atter is from tip. On the lateral surface its distance from the dorsal profile as about onefourth that from the ventral profile, at some 4-5 pores behind this about three-tenths, at vent about one-third followed by a noticeable downturn, at halfway between vent and end a little less than half, at termination half. The extension from the flank on to the top of the head takes the form on cach side of an outwardly convex arc of 5 evenly spaced pores, the two arcs joined anteriorly by a median pore at level of end of gape.

\section{Cephalic pores}

The dorsal, lateral and ventral surfaces of the head bear small simple pores regular1y arranged: these have not previously been described in Tasmanian material. On dorsum three pairs on snout, first shortly in advance of the level of the tubular anterior nostril, second between anterior and posterior nostrils, third between latter and front of orbit; a pair near posterior one-third of interorbital; a widely spaced pair just behind eyes, followed by a median pore, its distance behind them subequal to the interval between them. On lateral surface of head, close to ventral border, a row of four, evenly spaced, the distance between the first and last subequal to that of the first from tip of jaw, the second and third below the eye; in an upward and forward line from the fourth two other pores, the lower behind eye by about half eye at level of middle of eye, the upper the postorbital pore already noted as occurring on top of head visible also in 1 ateral view. On ventral surface in larger individual four pairs in advance of eye, interspace between first and second rather less than half interspaces between second and third and third and fourth; one pair about level with posterior border of orbit: in smaller individual nine pores arranged irregularly, perhaps interpretable as four pairs, the members set very obliquely instead of directly opposite, together with a hindmost azygous pore.

\section{Family NOMEIDAE}

The Handbook (Munro 1958b) listed as Australian nine members of the family Nomeidae (in some texts Psenidae), of which three are reported from Tasmania, (a) warehou or snotgall trevalla, Seriolelza brama (Günther, 1860); (b) mackerel trevalla or snotgall trevalla, Seriolezza macuZata (Forster, 1794); (c) Patagonian silver trevalla, Seriozezza porosa Guichenot, 1849. The earliest published Tasmanian catalogue (Johnston 1883) noted (in Carangidac) three species, Neptonemus brama Gïnther, 1860, N. dobula Gïnther, 1860 (which has Tasmania as type locality), N. trevaze Castelnau, 1872: of these the first is species (a) above, the second, recognized in the Check-list (McCulloch 1929) as a valid species, is in the Handbook treated as a synonym of (c), while Castelnau's species is generally synonymized (as in the Check-List) with (a). In his second catalogue Johnston (1891) had the same species, with a note of interrogation following Castelnau's species. Lord $(1923,1927)$ and Lord $\&$ Scott (1924) 1isted (in Stromateidae) four species, namely, (a) as above, Seriolezza punetata (Bloch \& Schneider, 1801), recognized in the Check-List but treated in the llandbook as synonymic with (b), $S$. dobula, adding Hyperogzyphe johstonii (Morton 1888) (type species of the genus Eummetopos Morton, 1888; type locality Tasmania). The last-named does not appear in the Handbook, being represented there by H. porosa (Richardson, 1845) and being transferred from Nomeidae (in which both Morton's and Richardson's species are accommodated in the CheckmList) to Centrolophidae; in his general review of the stromateoid fishes Haedrich (1967) also refers Hyperogzyphe Günther, 1859 to Centrolophidac, treating the two species noted above, together with the New Zealand Seriolezla amozus Griffin 1928, as junior synonyms of Perca antaretica Carmichae1, 1818 (type locality Tristan da Cunha). 


\section{E.O.G. Scott}

At present the general taxonomic position in regard to a number of stromateoids would appear certainly to be in a state of indecision and perhaps of some confusion, stemming in part from the limits of the relation between Schedophizus Cocco, 1829 and Sexiozelza Guichenot, 1848, conclusions on which affect the scope of the families Nomeidae and Centrolophidae. In a paper on the occurrence of semiozezza caemzea Guichenot, 1848 in New Zeal and waters McDowall (1980) referred it to Centrolophidae, at the same time observing "The scope of Schedophilus is in need of study and cannot be resolved here" In the present state of evident taxonomic uncertainty it is here deemed convenient (without espousing a definitive view on the matters in doubt) to follow the usage of the Handbook on the scope of the family Nomeidae.

Semolezta caemilae (type locality Juan Fernandez), reported from New Zealand by McDowal1, who regarded it as a senior synonym of Palinurichthys griseotineatus Norman, 1937 (referred by Haedrich(1967) to Sehedophizus) and the New Zealand Semiotelza tinro Gavrilov, 1973, has been reported by Last $\&$ Harris (1981) from cight stations in Tasmanian waters at which trawls were made by the Zechach in January-March 1979 . A further addition is"here made to the Tasmanian list, that of Cubiceps caemleus Regan, 1914 . This species was not included either in the Handbook or the Check-List, the genus Cubiceps Lowe, 1843, being represented in the former by only $\mathrm{C}$. baxtemi McCulloch, 1923, and appearing in the latter only in synonymy of a species of Psenes. Haedrich (1967) concisely defined cubiceps thus: "The combination of elongate body, long winglike pectoral fin, insertion of pelvics behind pectoral fin base, scales on top of head, cheeks, and opercles, and a patch of teeth on the tongue distinguishes Cubiceps from all other stromateoid genera".

Genus CUBICEPS Lowe, 1843

Cubiceps Lowe, 1843, p.82. Type-species, Seriola grandis Lowe 1843, by subsequent designation of Jordan E Evermann, 1896. [Lowe described his fish as a species in the genus Seriola, but noted (p.82) "Still it is not unlikely that a comparison of the two fishes [S. gracilis and S. bipinnulata (Quoy \& Gaimard)] may warrant ... their separation from Serioza into a genus, which may be called Cubiceps"].

Cubiceps: Haedrich, 1967, p.178 (synonymy, noting five other generic or subgeneric names, Altimostoma A. Smith, 1849, Navarchus Filippi \& Verany, 1859, Trachetocirrius Dounet, 1863, Mulichthys Lloyd, 1909, Mandelichthys Nichols \& Murphy, 1944, subgenus].

\section{4.}

PLATE 1 - Cubiceps caemzeus Regan, 1914. Radiograph from ventral aspect of a specimen $258 \mathrm{~mm}$ in standard length from Bicheno, east coast, Tasmania (Q.V.M. Reg. No. 1980/5/ $55)$.

\section{Cubiceps caemieus Regan, 1914}

Cubiceps caemieus Regan, 1914a, p.15. Type locality: Three Kings Islands.

Cubiceps caeruleus Regan, 1914b, p.19.

Cubiceps caemieus: Haedrich, 1967, p.81: McCulloch, 1923, p.15, pl.1, fig.3: Whit1ey, 1968, p.50: Hoese, 1976, p.436: But1er, 1979, p.231, fig.5.

?Cubiceps gracilis: Hutton, 1896, p.315. Non Semola gracilis Lowe, 1843.

Cubiceps gracizis: Waite, 1904a, p.162, and 1904b, p.200, and 1910, p.375. Non Semiota gracizis Lowe, 1843.

Cubiceps capensis: Haedrich, 1967, p.81 (part., all non-type material): Craddock \& Mead, 1970, p.33: Haedrich, 1972, p.79: Karrer, 1975, p.75: Ahlstrom et al., 1976, p.343: Pequeno, 1976, p.805. Non Altimostoma capensis Smith, 1849. 


\section{Distribution}

cubiceps caemileus is an antiboreal species. Of two species with which the present form has been confused, one, $S$. gracilis appears to be restricted to the Mediterranean and a region around the type locality, Madeira, while the other, $C$. capensis, shows some overlap with our species. A distribution map in Butler (1979, fig.6) showed two entries off the coast of New South Wales and two in New Zealand. These with others form a chain of records between South America and somewhat southwest of the southern tip of Africa and between Australia and the west coast of South America: in the Peru Current it has becn reported as far south as $19^{\circ} \mathrm{S}$. There are no records between South Africa and Western Australia. Butler observed "The absence of records from the south Indian Ocean may reflect the paucity of sampling in this region". Specimens from Lord Howe Island have been noted by waite (1904a,b), (as S. gracilis), McCulloch (1923) and Hoese (1976). The species is here for the first time reported from Tasmania.

\section{Tasmanian material}

In June $1980 \mathrm{Mr} J$. Billing observed several small fish in a rock pool at Bichono, east coast, Tasmania; one was speared and submitted to the Queen Victoria Museum for identification (together with an inquiry as to whether it was edible!). The specimen (Q.V.M. Reg. No. 1980/5/55), Ls 258 Lt 304, has been determined as Cubiceps caeruleus, and is the subject of the subjoined observations. It had been cleaned, with loss of the branchial arches, and it has suffered further damage, notably in the first dorsal. Members of the genus Cubiceps are typically oceanic fishes - regularly found in the stomachs of porpoises and tunas and sometimes taken on tuna lines and in lift net fisheries (Butler 1979; specific references cited) - and though there are occasional records of stranded individuals, e.g. McCulloch (1923), the occurrence of C. caemzeus in the littoral situation here noted would appear to be quite exceptional.

\section{Dimensions}

Except where otherwise indicated the following dimensions are all recorded as thousandths of standard length: they include a dozen items for which Butler (1979, table 1) gave ranges and means for seven species of Cubiceps, his values being given here in parentheses. Total length 1178. Length to origin of first dorsal $382(202-418,378)$, to termination $492(?)$; to origin of second dorsal 610 , to termination 899 ; to origin of ana1 $655(580-679,643)$, to termination 899 . Length to pectoral, front of base 236 , insertion of most advanced (uppermost) ray 271; length of fin, total 337, longest ray 329 ('pectoral fin length' $188-346,308$ ). Length to pelvic 357 ; length of fin, total 107, longest ray 97 ('pelvic fin length' 104-154, 120). Head 269 (216-365, 300). Orbit, longitudinal 62.4, vertical 69.8: as thousandths of head length 232, 259 ('orbit' 244-320, 276). Snout, from tip of upper jaw 62.0, from tip of lower jaw 64.0: as thousandths of head length 230,237 ('snout' 243-286, 270). Interorbital 77.5: as thousandths of head length $288(262-320,290)$. Length of upper jaw 77.5 : as thousandths of head length 288 (260-319, 295). Depth [width] at front of eye 139 [65.9], back of eye 190 [96.9], operculum 251 [116], dorsal origin 264 [116], vent 441 [109]; maximum 271 [120]; caudal peduncle, minimum 75.6 , at origin of caudal ridges 77.5 . Longest preserved dorsal spine, total 87.2 , without distal filament 82.2 ; longest preserved ray 71.7 ; last 465 . Longest preserved anal ray 58.1 , last 32.9 .

With the exception of snout relative to head (and barely here) our values fall within the ranges found by Butler, who examined some two score specimens: he pointed out the pectoral is longer than the head in examples of $L s>100 \mathrm{~mm}$. The marked differences between extreme values are very probably accounted for as being due, over and above individual variation and possible locality factors, to allometric growth, well known to be common in stromateoids (involving particularly the lengths of the head and the paired fins, the predorsal and preanal length and overall depth), the effect of which in some instances leads to notable differences in general form - e.g. as noted in Part XXIV (1978: 347) in Schedophilus huttoni (Waite 1910) with age the dorsal migrates caudad relative to the pectoral, the origin of the former being in advance of that of the latter in small individuals but later coming to be above it. 
Meristic characters

A. II, 23. D. XI (?, fin damaged), 27. P. 23, V.I, 5. C. $12+12+9 / 8$. Scales

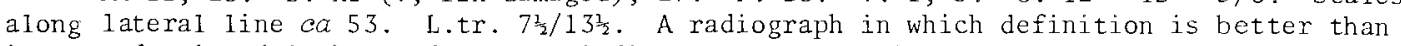
in reproduction (p1.1) would seem to indicate the appropriate vertebral count of 31 ( $13+$ 18 Haedrich, $12+19$ Butler).

General description of specimen

Dorsal profile a continuous curve from tip of upper jaw to insertion of uppermost caudal ray; height above base line from most advanced point on snout to middle of caudal peduncle at level of hypural joint reaches maximum at 0.4 of standard length, being here 3.3 minimum height; sum of anterior 5 deciles 1.27 sum of renainder. Sequence of descending magnitude of deciles: $4,5,6,3,7,2,8,1,9,10$. Ventral profile a continuous sweep, with more variation in curvature than dorsal profile; maximum depth below same axis equal at $0.3,0.4$ of length, here $4.4 \mathrm{minimum}$; sum of anterior 5 deciles 1.67 sum of remainder. Sequence of deciles $4,5,6,3,7,2,8,1,9,10$. Polynomial equations for body curvature (Appendix No. I). Caudal peduncle short, deep, stout, its depth 1.3 in its length, which is 2.7 in head.

Head moderate, 3.7 in $L s$, bluntly rounded, chin slightly in advance of most advanced point on upper jaw. Scales extend on to dorsum to cease at level of nostril, being bounded here by a sharply demarcated proconvex arc; about 20 scales in median line from level of opercular border, last 3-4 smaller than rest; this region bounded laterally to just behind level of hind border of orbit by a line of about 25 pores; between pores and upper rim of orbit a narrow naked fleshy strip along the middle of which runs the white supraorbital ridge, this being narrowly bordered above and below by blackish; at middle of eye squamous dorsal region with 7 lines of scales; naked area continuing round behind eye, irregularly minutely mamillated and ridged, its greatest width half an eye diameter, extending forward to become continuous with naked side and front of wholly naked, but randomly poriferous, snout; behind this region, and probably below it, head, including opercle, scaled. Nostril a smal1 subcircular opening with low rim, on horizontal level with upper onefifth of eye; direct distance from eye twice that from upper 1ip; internarial half interorbital. Maxilla just failing to reach level of front of eye; somewhat expanded distally, its greatest width about one-fourth length of jaw. Premaxilla not protractile. Supramaxilla absent. Posterior three-fourths of upper jaw overlapped by gelatinous preorbital, its margin entire. Lower jaw stout, bluntly rounded, projecting a trifle beyond upper. Even with mouth widely open angle of gape well in advance of eye, about at level of nostril, or below middle of lower jaw with mouth closed. Eye moderate, its horizontal diameter 0.9 vertical, 4.6 in head; about two and a half times as far from ventral as from dorsal profile; wholly covered with a somewhat bluish grey adipose sheath, exhibiting no indication of an extension forward around the nostril such as that noted by Haedrich (1967: 79) in a detailed diagnosis of the genus Cubiceps. Interorbital slightly exceeding height of orbit, subequal to depth of caudal peduncle, strongly convex transversely less so longitudinally. Whole opercle flexible, more or less membraneous, borders of the bones naked, translucent.

Opercular border entjre; a subtriangular process at level of middle of eye, basal width, about half pupil, thrice length, the slightly concave sides largely formed by two small spines, embedded save at short acute tip, a similar but almost straight spine between them, also projecting slightly at a distance subequal to base of this process the border bears a small translucent linguiform process, its distal border briefly bilobed, embedded in it an opaque black structure, barely more than a tapering streak less than $1 \mathrm{~mm}$ long, not exposed distally, which may represent an incipient or a vestigial spine: border between these two processes, shown strongly concave in the illustration accompanying the only account of an Australian example of this species, that of McCulloch (1923), is here decidedly convex. Preoperculum differing markedly from its representation in that figure, wholly lacking the backward sweep at the angle; reaching its greatest backward extension barely below level of orbit, being here slightly rounded; descending for about an eye diameter a little obliquely down and forward, almost straight overall, slightly concave in lower half; after forming a slight angle continuing, more or less linearly, at an 
angle of about $135^{\circ}$ for an eye diameter, this section irregularly and minutely denticulate; thereafter forward and upward gently convex to termination below front of eye.

Teeth in upper jaw in a single series, small subconical mostly somewhat recurved, spaced, decreasing in size backward; in lower jaw teeth similar but lateral teeth somewhat stouter. Teeth on vomer large circular flatly mounded ('knobby'), about two score, forming an elongate subelliptical patch, width, greatest behind middle, about one-third length, which exceeds half eye; whole patch 1 ight orange, conspicuous against dark grey or black of surrounding jalate. A line of about eight small teeth on each palatine, apparently not reaching forward to front of vomerine patch. Tongue smooth, very broadly rounded in front; on its hind half an elliptical orange patch of teeth, of similar size to vomerine patch of teeth but more bluntly rounded at ends; teeth somewhat more closely set. On the glossohyals two pale orange patches, somewhat shorter, decidedly narrower, than patch on vomer, teeth smaller, separated anteriorly by about their own length, diverging posteriorly.

Dorsal fin originating at $0.38 \mathrm{Ls}$, well behind pectoral origin, slightly behind pelvic origin (contrast McCulloch's plate); fin damaged; apparently with 11 spines. Second dorsal originating at $0.60 \mathrm{Ls}$, somewhat in advance of anal origin, rays decreasing in length caudad. Anal ending directly under second dorsal, last two rays elongated. Pectoral with upper anterior end of base just in advance of tip of opercular process; fin narrow, winglike, extending to within an eye diameter of anal origin; first ray onefourth, second half, length of third (longest), so closely adherent to one another as to make upper border a single rigid gently convex rib. Examination of the figure of this species in the review of the genus Cubiceps by Butler (1979, fig.5) would suggest that the pectoral is there turned upside down with the smooth leading edge directed ventrally; such a curious reversal obtains with the right pectoral of our specimen, the abnormal posture now being so thoroughly established that the fin cannot be restored to its usual position without risk of damage. Pelvics small, pointed, extending less than halfway to vent, anterior two-thirds or more fitting into a wide groove; for lengths of rays see below. When the specimen is viewed from the right side the upper caudal lobe is seen to be folded over the lower, obscuring some four-fifths of it: such overlapping is noted by Haedrich as not uncommon. All scales have been lost. From its origin a little above level of highest point on supraorbital ridge, where it is two-thirds eye diameter below dorsal profile, the lateral line rises, in the course of rather less than half a head length, to be only half eye diameter from profile, a relation it maintains to second dorsal origin, behind which distance from profile continuously decreases to be half as great at fin termination.

Portions of the subdermal canal system on the flanks (the visibility of which must vary with circumstances of preservation) that are here apparent are as follows: a shallow off-white groove, of maximum width $0.5 \mathrm{~mm}$, extending almost linearly from upper angle of operculum to middle of caudal base, above and below this a narrower line, combined width of these about half pupil diameter; between levels of pelvic insertion and vent about a dozen forwardly convex whitish bands, extending to a maximum of halfway towards dorsal profile and of three-fourths of way towards ventral profile; between these arcs a complex system of finer reticulating light lines. An arc of pores fringing lower lip; others in a row just external to either edge of the isthmus, which extends virtually to tip of lower jaw. The specimen quite clearly exhibits the characteristic 'stromateoid look' regarded by Haedrich as constituting a valid, if somewhat trivial taxonomic criterion: "It is a fat-nosed, wide-eyed, stuffed-up look, smug and at the same time apprehensive".

\section{Coloration}

General color, in total absence of scales, light reddish brown, each scale pocket outlined in dark brown, most extensively at posterior border. Naked portion of head fawn, in parts dusky. Dorsal spines and rays very dark straw; anal rays somewhat greenish yellow with rusty maculation; pelvic yellow with extensive dark brown spotting; pectoral pale yellow tending to brownish in upper part; caudal medium brown, darker in outer rays. 


\section{E.O.G. Scott}

Ventral rays

The lengths of all five rays are a function of their reverse serial numbers,

$L=b N^{\prime}(k)$, where $N^{\prime}=$ number of ray, counting cephalad.

$\log L=0.2284 \log N^{\prime}+1.8546 ; \quad t 11.397^{*}$; estimated (measured) lengths, TLs, 72(70), $84(86), 92(93), 98(99), 103(101)$.

A relationship of this type has been reported in these contributions for a number of unrelated species, the modal set of rays involved, however, being $\{1-4\}$. In a recent paper (Scott 1982) a relationship of the form $L=b N(k)$ has been examined for Creedia haswelli (Ramsay, 1881), in which there are only four rays, to investigate which ray is likely to have been lost in this species from the full complement in the Creediidae, recorded by Nelson (1978) as five.

Body profiles

Polynomials have been calculated for the dorsal and ventral profiles as specified by 10 equidistant measurements of height above and depth below an axis from most advanced point to middle of caudal peduncle at hypural joint (Appendix No.I).

\section{Family REGALECIDAE}

(P1s 2-4)

In its broad connotation, as accepted by Greenwood et al. (1966) in their provisional classification of living teleosts, that is, with the inclusion of a small group of lampridiform fishes placed by some Australasian authors, e.g. Whitley (1933, 1968), Munro (1957b) in a separate family Agrostichthidae, originally proposed by Phillipps (1924) to accommodate the New Zealand Agrostichthys parkeri Benham, 1904, the family Regalecidae is represented in Tasmania by two species, the southern oarfish, Regalecus pacificus Haast, 1878, and Benham's streamer fish, Agrostichthys benhami Scott, 1934.

\section{KEY TO REGALECIDAE RECORDED FROM TASMANIA}

Length $<30$ height; no teeth; upper profile of head concave; maxillary plate deeper than long; eye $>3(\doteq 4-5)$ in head;

P. $>10$ (12-14); elevated anterior section of dorsal with

$>6(8-20)$ rays; lateral line descending to within $>\frac{1}{4}$

$(\doteq 1 / 3)$ of total depth from ventral profile; size large ( to $>5 \mathrm{~m}$ )

Length $>30(\doteq 45)$ height; teeth in lower jaw (2) and on vomer vomer

Regalecus pacificus

(3); upper profile of head convex; maxillary plate

longer than deep; eye $<3(\doteq 1.7)$ in head; $\mathrm{P} .<10$ (8);

anterior elevated section of dorsal with $<6$ (3) rays;

lateral line descending to $<\frac{1}{4}(\doteq 1 / 6)$ of total depth

from ventral profile; size small ( $1 \mathrm{~m}$ )

........... Agrostichthys benhami

Genus REGALECUS Ascanius, 1772

Regalecus Ascanius, 1772: 5. Type-species, Ophidium glesne Ascanius.

Regalecus pacificus Haast, 1878

Regalecus pacificus Haast, 1877, p.646. Nomen nudum.

Regalecus pacificus Haast, 1878, p.246, p1.7. Type locality: New Brighton, New Zealand.

Regalecus pacificus: Whit1ey, 1933, p.70, fig.2, and 1948, p.16, and 1962, p.64, unnumbered fig., and 1964, p.41, and 1968, p.45: Munro, 1957b, p.64, fig.451 (two figures so numbered): Marsha11, 1964, p.125, p1.29, fig.136, and 1966, p.178, p1.29, fig.136.

Regalecus gladius: Günther, 1861, p.308: A11port, prior to 1882; Nacleay, 1882a, p.55:

Johnston, 1883, p.123, and 1891, ibida. (1890), p.34 (p.13 of reprint). Non Gymetrus gladius Valenciennes, 1835. 


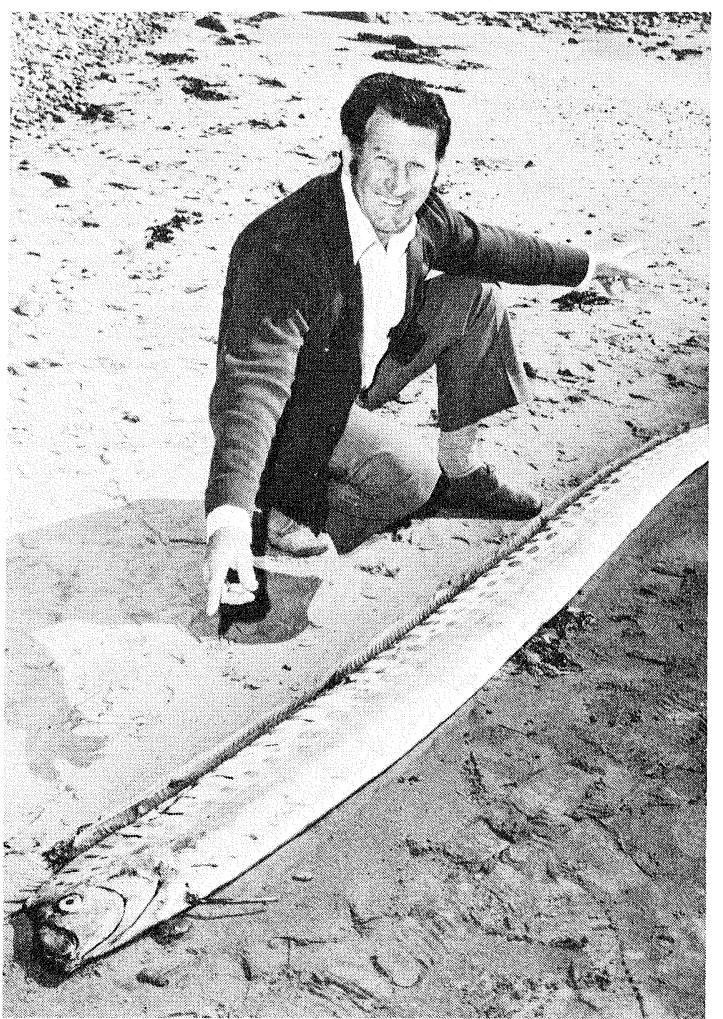

PLATE 2 - Regalecus pacificus Haast, 1878. A specimen secured at Mersey Bluff Beach, Devonport, northwest coast, Tasmania by Mr D. Heywood in December 1977. Approximate total length $3 \mathrm{~m}$. (Photo: Advocate.)

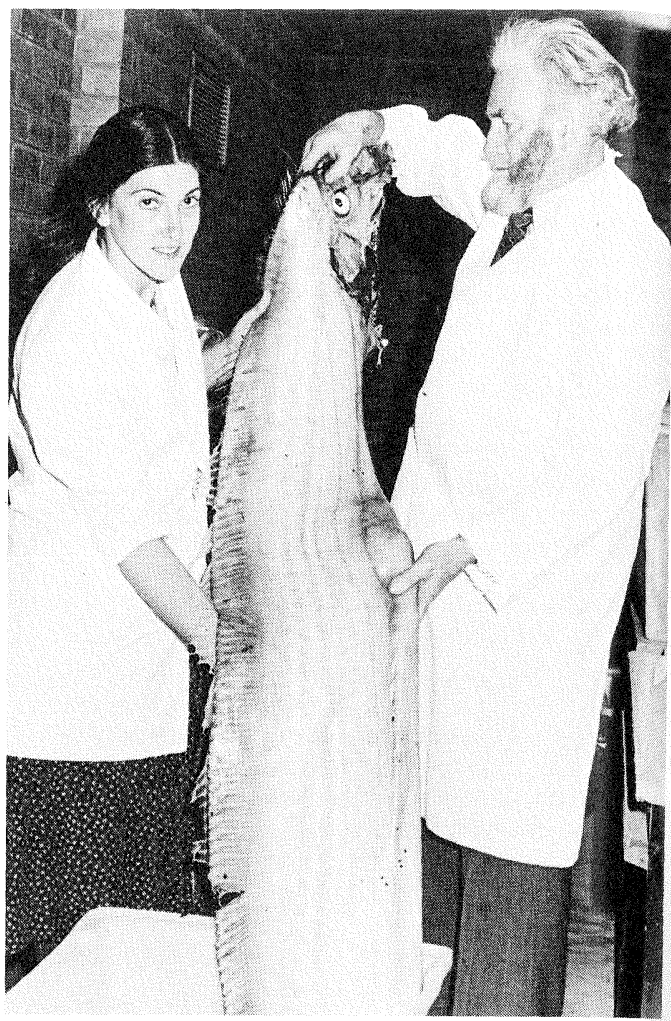

PLATE 3 - Regalecus pacificus Haast, 1878. A specimen found stranded by $\mathrm{Mr} \mathrm{K}$.

Adamson and Mr N. Chilcott at Low Head, Tamar estuary, north coast, Tasmania in October 1981 (Q.V.M. Reg. No. 1981/5/58). Total length as preserved $3.55 \mathrm{~m}$, estimated length when perfect 5.4-5.9 m. (Photo: Examiner.)

Regalecus glesne: McCulloch, 1921, p.34, p1.26, fig.125a: Lord, 1923, p.65, and 1927, p.13: Lord and Scott, 1924, pp.9,14, unnumbered outline fig.: McCulloch, 1929, p.138. Non Regalecus glesne Ascanius, 1772.

Regalecus banksii: M'Coy, 1887, p.169, p1.145: Lucas, 1890, p.32. Non Gymetrus banksii Valenciennes, 1835.

Regalecus banksi: Marsha11, 1964, p.125, and 1966, p.178.

Gymetms banksii: McCulloch, 1929, p.138: Non Gymnetrus banksii valenciennes, 1835.

Regalecus argenteus Parker, 1883, p.520. Nomen nudum.

Regalecus argenteus Parker, 1884, p.284, p1s 23,24. Type locality: Moeraki, Otago, New Zealand.

Regalecus argenteus Parker, 1888, p.20, p1.5.

Regalecus grizlii: Forbes, 1891, p.192: McCulloch, 1929, p.138. Non Gymetrus grillii Lindroth, 1798.

Regalecus remipes: McCulloch, 1929, p.138. Non Regalecus remipes Brunnich, 1788. Gymetrus howkenii: McCulloch, 1929, p.138. Non Gymetrus hawkenii Bloch, 1795. Regalecus masterii De Vis, 1891, p.13. Nomen nudum.

Regalecus masterii De Vis, 1892, p.109. Type locality: near Tweed River, Queensland. Regalecus masterii: McCulloch, 1929, p.138. 


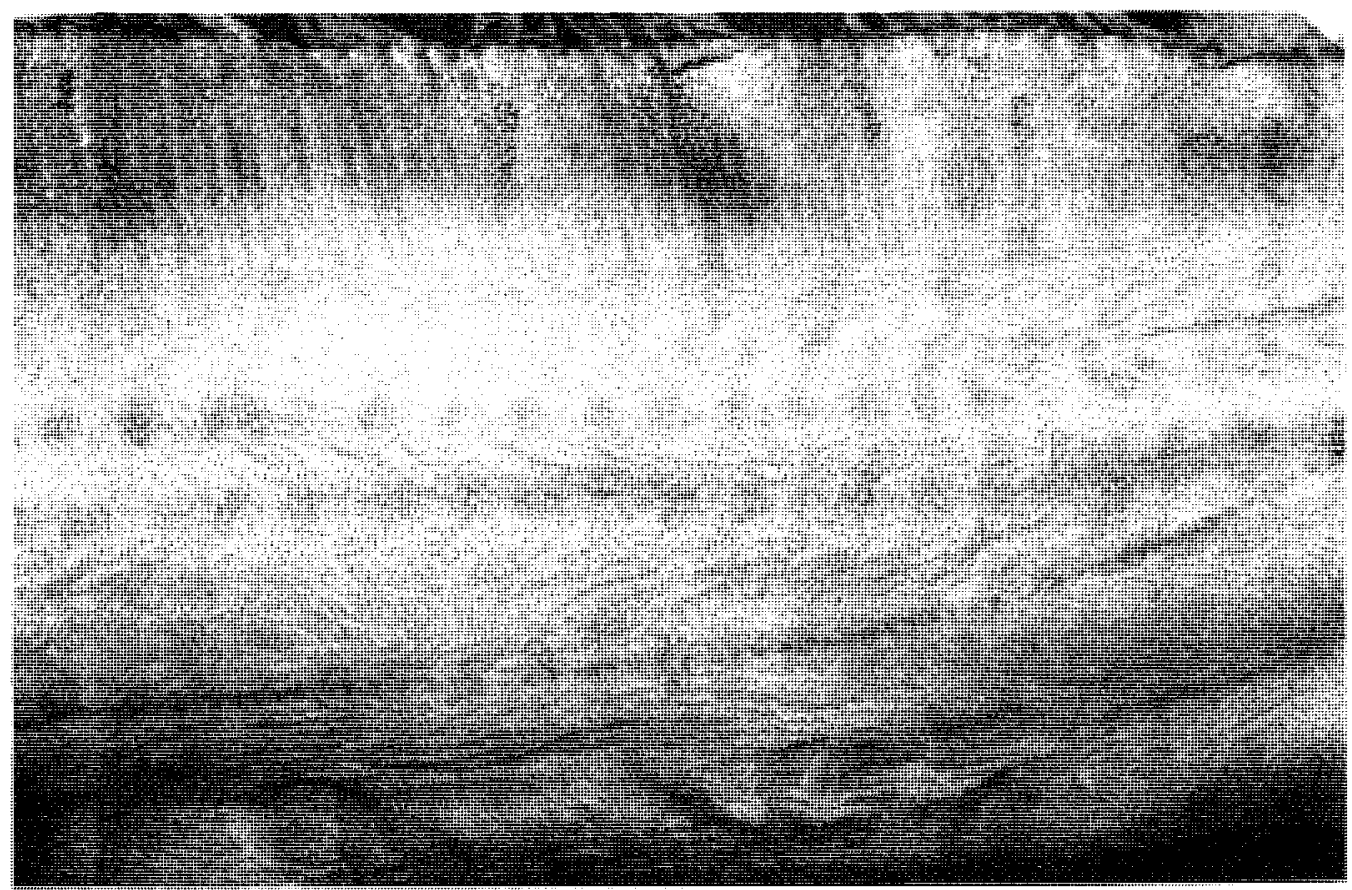

PLATE 4 - Regalecus pacificus Haast, 1878. Detail of portion of the posterior region of the Low Head specimen of which a general view appears in plate 3 . Note especially paired markings along dorsal border (Q.V.M. Reg. No. 1981/5/55). (Photo: Nuseum).

\section{Note on synonymy}

While the decision taken in the Check-List (McCulloch 1929) to represent the Australasian oarfish by a taxon (Regalecus glesne Ascanius, 1772) bestowed on a northern hemisphere fish has inevitably led, given the mere nature of a checklist, to the formal introduction to the Australian taxonomic scene of some species names of only marginal significance, the main trend in the Australian literature has followed, with very few exceptions (the most noticeable being the adoption by $M^{\prime} C o y$ (1887), of Valenciennes'

$R$. banksii - ascribed by M'Coy to Cuvier), a regular chronological trinomial sequence. In the last century local texts employed $R$. glaaius Valenciennes, 1835 (based on "Cepota gladius" Walbaum, ascribed by authors, in accordance with the convention then current, to Cuvier and Valenciennes, with reference to fistoire Naturelle des Poissons); during the first three or four decades of the present century $R$. glesne Ascanius, 1775 was in general use; while in the more recent years the validity of Haast's $R$. pacificus, with type locality New Zealand, has been almost universally accepted. Two additional names for the Australasian form have been proposed, $R$. argenteus by Parker in New Zealand and $R$. masterii by De Vis in Queensland.

Recent strandings

Our knowledge of this deep-sea oceanic species is largely based on specimens cast up from time to time, often in a damaged state, on the beach. Günther $(1880: 523)$ noted that not more than 16 strandings were recorded on the coasts of Britain between 1759 and 1878. The first record of a Tasmanian example in the formal literature is provided by Johnston $(1883$, p.123): "specimen examined, 14 feet $[4.3 \mathrm{~m}]$ long, captured at the Penguin [town, on northwest coast, now simply known as Penguin], Tasmania". Lord and Scott (1924: 
46, outline figure) state "A specimen secured in a fish trap at Stanley, a sketch of which is in the Tasmanian Museum, gives the dimensions as follows:- Length, 14 feet [4.3 m]; greatest depth, 12 inches [30 cm]; breadth, 2 to 3 inches [51-76 mm]". The total length is said to exceed 23 feet [7 m] (Whitley 1962). Further local strandings have from time to time been reported in the press, but no systematic list of these exists.

Two recent strandings are here recorded: these individuals are of some special interest, making unusual contributions to the curious problem of the color pattern in the Australasian oarfish.

(a) A specimen secured at the Mersey Bluff Beach, Devonport, northwest coast, in 1977. The Advocate of 8 December reported that Mr Don Heywood, a visitor from Chadstone, Victoria, noticed the fish splashing about in the shallows and dragged it out by hooking his thumbs in the gill slits; the length was given as $3 \mathrm{~m}$. By courtesy of the editor of the newspaper, Mr D.J. Cherry, an excellent photograph of this fish is here reproduced (pl. 2)

(b) The Examiner of 14 October 1981 reported the finding by Mr Kerry Adamson and Mr Norm Chilcott, of Georgetown, of an example washed ashore, still fresh and bleeding, at Low Head, Tamar estuary, north coast; the length was given as $4 \mathrm{~m}$ (see below), the weight as ca. $18 \mathrm{~kg}$. This fish, the newspaper photograph of which (pl.3) together with a photograph taken later (pl.4) showing color pattern near the dorsal border of the trunk, is preserved in the Queen Victoria Museum, Launceston (Reg. No. 1981/5/58; listed as presented by J. Hooper).

\section{Color pattern}

Specimen (a). The conspicuous and extensive ornamentation of the Devonport specimen, well shown in the plate, exhibits some unusual features. It consists chiefly of closely set spots; near the middle of the length these are arranged in 4-5 rows, of which the upper 2 are the most prominent, those of the superior row, hard against the dorsal profile, being rounded or subelliptical vertically, those of the next row rounded or a trifle elongate longitudinally. In the anterior one-third or more the markings of the upper row tend posteriorly to assume the form of subvertical bars, with those behind the head narrowing to streaks. Apart from a few indistinct and irregular smudges for a head length or so behind the head the flank is without markings in its lower part, the height of this immaculate band being close to half the total height just behind the head, the proportion decreasing caudad to perhaps one-third at the hindmost point included in the plate (as the picture appeared in the newspaper it extended to the pointed end of the fish, the small additional section apparently lacking ornamentation). The most notable differences between this pattern and that of the specimen, 13 feet 7 inches $(4.1 \mathrm{~m})$ in length, taken in the sea between Tasmania and Victoria in 1878, and figured, as $R$. banksii, by $M^{\prime}$ Coy [this figure adopted as definitive by Marshall $(1964,1966)$ and - with some modifications, which, however do not involve the color pattern, by whitley (1962)] are as follows: spots extending forward to head instead of being confined to posterior threefifths; spots not extending to ventral profile; absence of the narrow parallel horizontal lines ( 6 in anterior part of trunk); absence of "about 19 vertical black streaks, half an inch [12-13 $\mathrm{mm}$ ] in width, of variable length [that] cross the anterior half of the body." From the New Zealand type of $R$. pacificus as illustrated (Haast 1878, pl.7) it differs greatly in one positive character, presence of rounded spots, and in three negative characters, absence of longitudinal bars, of irregular oblique dark markings, of the line of inverted $\mathrm{V}$-shaped markings along dorsal border. It contrasts sharply with the figure of $R$. glesne reproduced in McCulloch's New South Wales Catalogue (1921, p1.11, fig.125a) and with other representations of the European oarfish depicting it as wholly covered with small evenly distributed round spots. No color pattern is indicated in the local figures of Lord and Scott (1924, unnumbered fig. on p.46), Munro (1957b, fig.451), Scott et al. (1974, unnumbered fig. on p.98), the three texts, however, specifying dark wavy or irregular lines and spots. 
Specimen (b). The Low Head individual exhibits one feature of much interest, the presence 11 ong the whole length of the dorsal border of a series of closely set vertically elongate narkings each consisting either of two subparallel dark bars, or, more particularly towards the hind end of the fish as preserved, of two outwardly convex arcs converging at the upper end or meeting there to form a narrow lancet arch - similar markings are shown in laast's plate of his type but are not evident in any Australian figure to come under notice. This ornamentation is clearly apparent in pl.3 and is depicted in detail in pl.4. The width of the pier of the arch is commonly somewhat less than its distance from its fellor and more noticeably less than the distance between adjoining arches. Shortly behind the head, where the total depth is 260 , the height of the marking is 55 , its maximum width 15; at the truncated end of the specimen, where total depth is 150 , the height decreases to 40 , the width remaining much the same. In different parts of the body the arch ranges from light to dark grey, the interspaces then usually very pale grey or pearl, or, particularly posteriorly, from light to moderate brownish (at times with a reddish tinge), the lighter interspaces sometimes in part, especially superiorly, suffused with pale brownish. The remainder of the pattern is intermediate between that in local illustrations, the lower of the longitudinal stripes resembling the narrow lines in M'Coy's plate, the broader upper approximating the dark bands in Haast's plate, with, however, the uppermost including in it a sequence of dark spots, more regularly arranged than those in the former figure, approaching those of our Devonport specimen. A very slender black line, not evident in any representation of the fish, delimits the dorsal border throughout the length.

\section{General features}

Some general features of specimen (b) may be noted. Length: the total length as preserved is approximately $3.55 \mathrm{~m}$, the hinder portion being missing beyond a point at which the depth is 150 or 0.58 depth near pelvic insertion. Examination of published figures suggests such a proportional depth could be expected to occur at around about 0.6-0.65 of the total length, the possible intact length of the present individual being $5.4-5.9 \mathrm{~m}$. These length values would yield depth (maximum 300) in length 18-20 (M'Coy 22, Munro 23-30) and head (damaged, estimated length 240) 23-25 in 1ength (M'Coy 22, Munro 21). Orbit: longer than high, $42 \times 35$ or 5.7 (M'Coy 5.0) in head. Dorsal rays behind crest: slender, acuminate, tolerably flexible, largest measured 78 . Dorsal crest: the elongate anterior rays of the dorsal forming the characteristic cephalic crest would appear to number about 8 in specimen (a), the first 4 the stouter; however, a definitive count is not possible. In (b), in which only the bases of the rays remain in all except one (and that, a slender, highly flexible lash, imperfect at a length of $165 \mathrm{~mm}$ ) the sequence is: 1st (just possibly 2nd), stout, basal diameter $>2 \mathrm{~mm}$; 3rd fine, diameter $>1 \mathrm{~mm}$; 4 th-6th $(?+)$, diameter $\doteq 2 \mathrm{~mm}$. The dorsal profile above the anterior part of the head shows a remarkable diversity of patterns, some of which were assembled by Parker $(1884$, pl.24). As illustrated the dorsal fin may or may not be differentiated to form a crest, which may be single or may consist of two sections or sheaves; it may be highest in front, or near the middle, or may present two peaks: rays may be simple, spatulate, distally lobate or noded or some combination of these conditions. Some variants are noted below.

(a) No distinct crest. M'Coy (1887, 1.145$)$ - a modification of M'Coy by Whit1ey (1962, unnumbered fig. on p.64) has a falcate outline (base exceptionally long, extending well behind head), with possible indication on hind border of base of about a dozen rays; Parker (p1.24, fig.8). (b) Crest a single sheaf. Haast (1878, pl.7), 8 simple rays of variable height; Parker (p1.24) 1 (7th ray) simple (fig.5), 11, decreasing caudad, simple (fig.4), 10, all spatulate except 2nd, 4th highest (fig.4); Lord and Scott (1924, unnumbered outline figure on p.46) 9 simple rays, highest anteriorly; Munro (1957b, right hand figure of two numbered 451), also scott et al. (1974, unnumbered figure on $\mathrm{n} .98$ ), 8 simple or somewhat lobate distally, decreasing caudad. (c) Crest distinguishable into two sections. The type of $R$. argenteus Parker, 1884 would seem to belong here, the general view of the head (p1.24, fig.l) showing, in succession caudad, 5 intact simple rays decreasing backwards, 4 stouter rays ( 2 imperfect), 7 th and 9 th with small foliate distal appendages, in 7 th together with an irregular membranous fringe on posterior edge of shaft (detail of ray in fig.2), these 9 rays followed by bases only of 6 others; Parker (pl.24, fig.6) 
5 simple, decreasing caudad, 7 (1st tallest in $f i n$ ) with small lanceolate distal appendage, decreasing caudad; McCulloch (1921, pl.26, fig.125a), a similar arrangement; Whitley (1933, fig.2; separate figure of head of a New Zealand specimen) 5 simple, decreasing caudad, 9 (lst tallest in fin) regularly noded, about a dozen nodes in tallest ray, this figure reproduced in Handbook (Munro 1957b, left hand figure of two numbered 451) (shaft of pelvic also noded). The occurrence of this curious range of pattern in the cephalic section of the dorsal fin, to which our specimen (b) adds yet another variant, remains without apparent explanation.

Pectoral: represented only by 12 stout stumps, anterior border of base in advance of level of opercular border by about one-third eye diameter. Pelvics: imperfect, reduced to somewhat compressed rigid vitreous rods (length 85,95 ), basal diameter 7 , inserted in contiguous fleshy sacs 15 in diameter, behind head by about an eye diameter. Maxillary plate: elongate subtriangular, length 75, 2.2 (Munro "twice") width, 33. Preoperculum (only other opercular bone intact): vertical extent 55, longitudinal 110 , chord 95 . Tuberculation: the integument is everywhere tuberculate, the size and density of the tubercles varying irregularly somewhat at different parts of the length, but disposed in a more or less regular fashion at a given region ( 1.4$)$, the sequence from the dorsal profile downwards being, briefly before the end of the specimen as preserved, as follows. In the upper two-fifths of the flank - this band including and extending somewhat below the paired markings - the tubercles of the upper part are small, numerous, irregularly disposed, $>20 / \mathrm{cm}^{2}$, those further down tending to become arranged in vertical lines along and between the markings; in the half of the flank below, in which 4 or 5 low longitudinal ridges are developed (bearing the dark bands visible in pl.3), the tubercles tending to be flatter and larger on these, about $12-15 / \mathrm{cm}^{2}$, than on the interpsaces. In the upper part of the ventral one-tenth they become very numerous, minute, $40-50 / \mathrm{cm}^{2}$, while below them are 2-3 rows of stout closely set mammilliform processes, 14-16 in a line of $50 \mathrm{~mm}$; the free downward projection of some of these results in the ventral profile being denticulate a condition clearly apparent in Haast's plate of the type and in some representations of the palaearctic species, e.g. Goode and Bean (1895, pl.117, fig.395).

\section{Fami ly CARANGIDAE}

Up till 1978 four members of this family (which has at various times been, partly or wholly, designated Seriolidae, Juvenellidae, Nematistidae) currently regarded as valid species were known to occur in Tasmanian waters: Naucrates ductor (Linné, 1758), Seriola grandis Castelnau, 1872, Usacaranx nobilis (Macleay, 1881), Trachurus declivis (Jenyns, 1841). The synonymy of twice as many names occurring in the local faunal lists was sorted out in Part XXV (1979), which also provided a key to the authentic Tasmanian assemblage: it was there incorrectly stated that Castelnau's species escaped the noticc of the CheckList (McCulloch 1929). In that paper a fifth species was added, Trachurus novaezelandiae (Richardson), there reported as Trachurus moculzochi Nichols, 1920.

\section{Genus TRACHURUS Rafinesque, 1810}

Trachurus Rafinesque, $1810, \mathrm{p} .41$. Type-species, Trachurus samms Rafinesque $=$ Scomber trachurus Linné.

Trachurus novaezelandiae Richardson, 1843

Saurel de la Nouvelle-zéland Cuvier (in: Cuvier and Valenciennes), 1833, p.26; non binomen. Trachurus novaezelandiae Richardson, 1843a, p.21 = Cuvier, 1833. Type 1ocality: New zealand.

Trachurus novaezetandiae McCu11och, 1921, p.62: Stephenson and Robertson, 1977, p.251, figs $1-3$.

?Scomber clupeoides: Richardson, 1843a, p.26, and in: Trav. N.Z. (Diffenbach), 1843b, p.210, et Solander MS. Type locality: Dusky Bay, New Zealand.

?Trachurus clupeoides: Whitley, 1968, p.57.

Caranx trachums japonians Temminck \& Schlegc1, 1844, p.109, fig.1. 
Type locality: shores of Japan.

Trachumus declivis: McCulloch, 1915, p.125, fig.34(2); Wakiya, 1924, p.146: Griffin, 1932, p.124, fig.18. Non Trachurus declivis Jenyns, 1842.

Trachumis japonicus: Nichols, 1920, p.479: Wakiya, 1924, p.144: Aleev, 1957, p.220, fig. 4: Suzuki, 1962, p.213.

Trachums meculzochi Nichols, 1920. p.479; new name for Trachurus declivis: McCulloch,

1915; non Trachurus declivis Jenyns, 1842. Type locality: mouth of Wide Bay,

Queensland; Investigator Strait, South Australia (Endeavour).

Trachums meculzochi Munro, 1958c, p.124, fig.808: Berry and Cohen, 1974, p.194: Scott, 1979, p. 121.

Trachume trachurus: M'Coy, $1878, \mathrm{p} .25, \mathrm{p} 1.18$.

Additional Tasmanian material

This species was added to the Tasmanian faunal list in part XXV (1979) on the basis of a specimen, $L s$ 283, taken by Mr M. Watson in the Tamar estuary, north coast, during an Apex fishing contest, 26 February 1978 (Q.V.M. Reg. No. 1978/5/63). At the 1981 contest 29 March, two further examples were entered in the section Most Unusual Fish: (a) Ls 262, Lt 293, Miss K. Walker (Q.V.M. Reg. No. 1981/5/49) (b) Ls 267, Lt -, Mr R. Collins (1981/ 5/43). In April three examples taken by Mr J. Stockton in a fish trap at Penguin, northwest coast, were submitted to the Museum for identification; these were not retained, but a series of routine measurements was made on one specimen, (c) Ls 287, Lt 340. The 1978 specimen was reported as Trachurus meculzochi Nichols, 1920. In a recent review of the New Zealand representatives of the genus Stephenson and Robertson (1977) regard this as synonymic with $T$. novaezelandiae Richardson, 1843. Some of their nomenclatural conclusions are noted above. The acceptance of this status extends its distribution from temperate Australian waters to the shores of much of southeastern Asia.

Ventral rays

It was noted of the first recorded Tasmanian example "The ventral rays are somewhat unusual in increasing from 1st - farthest from spine, see Part XIX (1974) - to 5th; in a more common pattern 4th exceeds 5th". This departure from the modal pattern proves to be an individual peculiarity, the longest ventral ray in specimens (a) and (b) - no data available for (c) - being the customary 4th. The equations for these two examples with $L=$ their serial numbers $\{1,2,3,4\}$, with logarithms of both sets of magnitudes taken are as below:

$\log L=0.4604 \log N+1.8495 ; t 20.763^{* *}$; estimated (measured) 1engths, TLs, 71(70), $97(99), 117(119), 134(131)$.

$\log L=0.4631 \log N+1.8282,67(66), 93(97), 112(116), 128(124)$.

Family SCOMBRIDAE

Brief notes on the family are given in Part XXV (1979) and Part XXVII (1981).

Genus GASTEROCHISMA Richardson, 1845

Gasterochisma Richardson, 1845, P.346. Type-species, Gasterochisma melampus Richardson. Lepidothynnus Günther, 1889 , p.15. Type-species Lepidothymus huttonii Günther.

Gasterochisma melampus Richardson, 1845

(Text-figs 1-6)

Gasterochisma me Zampus Richardson, 1845, p.346. Type locality: Port Nicholson, New Zealand.

Gasterochisma melampus: Scott, 1981, p.135 (references and synonymy).

Additional material

Four occurrences in Tasmanian waters of this "very rare oceanic species"

(McCulloch 1922: 104) have been reported, all in this journal: Derwent estuary, Ls 838, Lt 991 (Johnston 1883 and in: Whitley 1929), Falmouth, Ls 372 Lt 459 (Scott 1979), 
Binnalong Bay, Ls 460 Lt 578 (Scott 1981), off mouth of Mersey, Ls 342 Lt 417 (Scott 1981). A fifth example, Ls $234 \mathrm{Lt}$ 292, found stranded between Greens Creek and Brooks Creek on 10 March 1981 by an Earthwatch expedition to the West Coast (Q.V.M. Reg. No. $1981 / 5 / 81$ ) is here noted.

\section{Proportions}

A number of body proportions of the present specimen, here marked with an asterisk, fall outside ranges previously reported - 1981 range shown in parentheses together with the specification, where available, given by the llandbook (Munro 1958a). Greatest depth in standard length $3.4^{*}(3.6-3.9,3.9-4.1)$. Head in standard length $3.8 *(3.9-4.0,4-4.1)$. Depth of caudal peduncle in head $6.4(6.4-6.8)$. Eye in head $6.1(7.3-3.4,5.5-7.4)$, in snout 2.3* (3.0-3.1). Pectoral in standard length $7.9 *(6.0-6.6)$, in head $2.1^{*}(1.5-1.6)$. Ventral in standard length $2.8^{*}(2.9-3.6)$, in head $1.4(1.3-1.4)$. First dorsal base in standard length $3.4(3.0-3.4)$, second dorsal base $8.2(8.0-11.0)$, anal base $14.6 *(10.7-$ $13.0)$

Variation with growth

It has long been known that this species exhibits significant variation during growth, including a remarkable decrease in the relative size of the ventral, an increase in the relative length of the pectoral and an inversion in the relative heights of the dorsals, the anterior fin being the higher in juveniles the posterior in adults. In Part XXVII (1981) data relating to these features were collated for the three examples reported in these contributions, together with the type-specimen, Lt: 203, Johnston's example, a New Zealand specimen, Lt 1 637, from Kaikoura (Waite 1912) and the ChaZlenger fish, Lt 1 644, type specimen of Lepidothynnus huttoni Günther, 1889 . It was found the characters are significantly linear on $L t$. Summary results, with the inclusion of the present example, are set out below; all dimensions in thousandths of total length.

\begin{tabular}{|c|c|c|c|c|c|c|c|c|c|c|c|}
\hline & 203 & 292 & 417 & 459 & 578 & 991 & 1637 & 1644 & $\mathrm{~mm}$ & & \\
\hline Ventral: measured & 331 & 363 & 264 & 284 & 270 & 147 & 97 & 71 & $y$ & -0.966 & $-2.034)$ \\
\hline estimated & 332 & 316 & 294 & 286 & 265 & 190 & 74 & 69 & & & \\
\hline Pectora1: measured & 110 & 124 & 127 & 123 & 133 & 135 & 149 & 168 & $r$ & 0.921 & 1.593) \\
\hline estimated & 112 & 120 & 124 & 125 & 128 & 140 & 158 & 158 & & & \\
\hline \multirow{2}{*}{$\begin{aligned} \text { Dorsal ratio: } & \text { measured } \\
& \text { estimated }\end{aligned}$} & 2.6 & 2.3 & 2.0 & 1.5 & 1.2 & - & 0.7 & 0.5 & $r$ & -0.901 & $-1.477)$ \\
\hline & 2.2 & 2.1 & 1.9 & 1.9 & 1.7 & - & 0.5 & 0.5 & & & \\
\hline
\end{tabular}

For the best straight lines for the equation feature on $L t$ the slopes are $-0.180,0.0279$, -0.00114 , the intercepts $369,112,24$.

Dorsal and ventral profiles and overall outline

Ten measurements of height above or depth below an axis from snout tip to middle of caudal peduncle at hypural joint, together with their sum, taken at equal intervals and recorded as thousandths of standard length; with parameters of the relevant equations of the form $Y=A+B N+C N^{2}+D N^{3}+E N^{4}(N=$ serial number of measurement caudad $)$ and estimates derived from these are set out in table 1.

Finlets

In the 1981 communication an investigation of the relative location, length and height of the dorsal and anal finlets was made with data for the Mersey individual, which was there first reported. In the largest individual, from Binnalong Bay, the finlets have suffered some distortion (probably as the result at some stage of temporary dessication), and dimensions other than the heights of the anal finlets cannot usefully be measured. Data for the Falmouth specimen are here reported along with those for the present West Coast example: they are found to be consonant with the data for the Mersey fish.

(a) Location of finlets. With the anterior point of insertion of the hindmost finlet taken as origin and successive distances back to the anterior insertions of the earlier finlets measured it is found these distances are an exponential function of the reverse 
TALELE 1

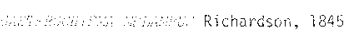

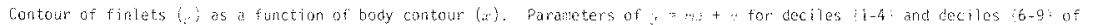

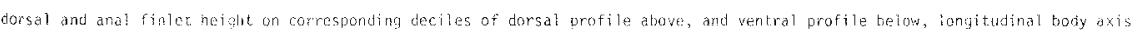

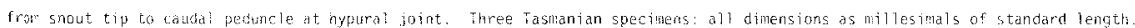

\begin{tabular}{|c|c|c|c|c|c|}
\hline \multirow[t]{4}{*}{$\therefore$} & \multirow[t]{2}{*}{ Regiun } & set & $m$ & $\because$ & $\therefore$ \\
\hline & & $1-4:$ & 0.0974 & -4.257 & $18.534^{\star \star \star}$ \\
\hline & \multirow[t]{2}{*}{ Worsal } & $\{6-9:$ & 0.0291 & 9.072 & $42.542^{\star \star \star \star}$ \\
\hline & & $\therefore 1-4:$ & 0.0876 & -5.172 & $17.213^{\star \star}$ \\
\hline \multirow[t]{4}{*}{234} & \multirow[t]{2}{*}{ Ventral } & $(6-9)$ & 0.00622 & 11,946 & 1.439 \\
\hline & & (1-.4) & 0.1303 & -1.043 & $11.476^{\star \star}$ \\
\hline & \multirow[t]{2}{*}{ Corsal } & $6-9 ;$ & 0.0201 & 11.013 & $23.632^{\star \star \star}$ \\
\hline & & $: 1-4$ & 0.0969 & -1.821 & $33.206^{\star \star \star}$ \\
\hline \multirow[t]{4}{*}{372} & \multirow[t]{2}{*}{ Ventral } & $|6-9|$ & 0.0253 & 10.819 & $8.092 * *$ \\
\hline & & $|1-4|$ & 0.0940 & 1.094 & - \\
\hline & \multirow[t]{2}{*}{ Dorsal } & $\{6-9\}$ & 0.0300 & 10.990 & $29.583^{\star \star}$ \\
\hline & & ||$-9\}$ & 0.0401 & 4.326 & $10.194^{\star \star}$ \\
\hline 342 & Ventra? & $\{6-9\}$ & 0.0162 & 10.290 & $7.891^{*}$ \\
\hline
\end{tabular}

Estimated (measured) height of fimlet $4.31(4.27) \quad 7.43(7.50) \quad 10.06(9.30) \quad 9.96(20.70)$ $\begin{array}{lllll}12.83(12.80) & 12.25(12.26) & 11.20(11.25) & 10.18(10.15)\end{array}$ $\begin{array}{lllll}4.28(4.27) & 6.91(6.61) & 3.93(8.92) & 10.06(10.21)\end{array}$ $\begin{array}{llll}12.92(12.50) & 12.85(13.02) & 12.53(12.89) & 12.21(12.00)\end{array}$ $6.96(6.70) \quad 20.38(10.95) \quad 13.05(12.80) \quad 14.01(13.95)$ $\begin{array}{lllll}14.13(14.20) & 13.89(13.80) & 12.98(13.00) & 12.00(12.00)\end{array}$ $\begin{array}{lllll}6.96(7.00) & 11.79(11.60) & 13.34(13.50) & 14.82(14.80)\end{array}$ $\begin{array}{llll}14.73(14.70) & 14.14(14.35) & 12.97(12.65) & 11.71(11.85)\end{array}$ - (8.33) - ( - ) - ( - ) - (14.25) $\begin{array}{lllll}14.95(15.00) & 14.23(14.20) & 13.21(13.15) & 12.25(12.30)\end{array}$ $\begin{array}{lllll}7.68(7.80) & 9.69(9.18) & 10.05(10.06) & 10.33(10.70)\end{array}$ $12.43(12.30) \quad 11.94(12.10) \quad 11.25(11.30) \quad 10.68(10.60)$

(i.e. cephalad) serial numbers of the finlets, $N^{\prime} ; \log L=k \log N^{\prime}+\log b$.

(1) Dorsa1. For the dorsal finlets of the present specimen $k=0.9596,10 \mathrm{l} b=1.5911$, $t$ 86.549***; estimated (measured) distances 39(38), 76(76), 112(114), 147(150), 183(182), 218(214). Parameters for the Mersey example reported on earlier 0.9943, 1.0391, $t 50.578^{\star \star *}$, for the Falmouth individual $1.2003,1.4300, t 59.432^{\star \star *}$. It will be noted that while the slopes for the largest and smallest examples are tolerably comparable (that of the latter being 0.965 of the former), that of the intermediate specimen is much greater than that of either of the others (1.207 smallest). A similar situation obtains for the anal finlets (parameters below).

(II) Ana1. For the present specimen $k=0.9002, \log b=1.5825, t 50.842 * * *$; estimated (measured) distances 38(38), 71(73), 103(105), 133(134), 163(159). Mersey,0.9660, $1.4883,33.538^{* * *}$; Falmouth, 1.2671, 1.2729, $131.197^{* * *}$.

(b) Length of finlets. With increasing development of a posterior process, finally assuming a pennon-like form, the lengths increase caudad. In a loglog plot they are linear on reverse serial number, $N^{\prime}$.

(I) Dorsal. For the present specimen $\log L=-0.2666 \log N^{\prime}+1.6643 ; t 8.939 * * *$; estimated (measured) lengths $27.5(25.6), 28.6(27.8), 30.1(31.2), 31.9(34.3), 34.4(35.5)$, $38.4(38.5), 46.2(43.4)$; parameters for earlier specimens, Mersey - 0.4722, 1.8413 , $t 48.353^{* * *}$; Falmouth $-0.2788,1.7736, t 26.860^{* * *}$.

(II) Ana1. Log $L=-0.3422 \mathrm{log} N^{\prime}+1.7391 ; t 28.391^{* *} ; 30.0(29.1) 31.6(32.1)$, $34.1(34.2), 37.7(38.5), 43.3(42.7), 54.8(54.7)$. Mersey $-0.4323,1.8148, t 31.151^{* * *}$; Falmouth $-0.3652,1.8014, t 29.008^{* * *}$.

(c) Height of finlets. The finlets initially increase regularly in height then regularly decrease. From a consideration of finlet height in the Mersey specimen in Part XXVII (1981) there emerged the highly interesting fact that the contours of the finlet series and of the body are strongly correlated, dorsal body with dorsal finlets, ventral body with anal finlets, each with markedly different anterior and posterior segments: it was then observed such form-patterns may well have significant biological and hydrodynamic implications not at present apparent. 
The relationships of the two outlines have now been further examined, attention being given also to the present specimen and the Falmouth fish (in the largest (Binnalong) individual some local deformation, probably occasioned by temporary dessication, precludes the making of satisfactory finlet height - and of finlet intcrspace while in the Falmouth fish the second dorsal finlet is imperfect). Data in table 2.

TRELEE ?

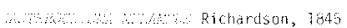

Dersal and ventrai profiles and oyerall outline of four iasmanion examples. Ten measuretients of height above or depth bellow all axis frok. snout tip to niddle of caudal peduncle at hygural joint, together with their sum, taken at equal intervals and recirded as thousand this of

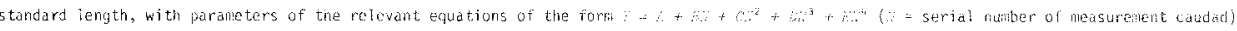
and es timates derived frori these.

\begin{tabular}{|c|c|c|c|c|c|c|c|c|}
\hline mm & gion & 4 & 3 & ? & i) & . & ? & Estimated (measured) height or depth, :r.:i \\
\hline & Dorsal & 45.8 & 47.35 & -3.942 & -0.5636 & 0.0461 & 0.9927 & 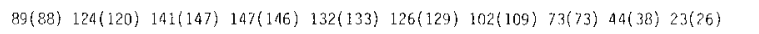 \\
\hline & Ventral & 87.2 & 13.56 & 9.303 & -2.2881 & 0.111568 & 0.9911 & $108(106) \quad[35(138) \quad 159(161) \quad 173(174) \quad 174(165) \quad 154(156) \quad 131(145) \quad 93(94) \quad 54(43) \quad 22(26)$ \\
\hline \multirow[t]{3}{*}{234} & 0veral7 & 132.9 & 61.09 & 5.224 & -2.8198 & 0.15977 & 0.9923 & $197(194) \quad 256(258) \quad 300(308) \quad 321(320) \quad 316(298) \quad 235(285) \quad 233(255) \quad 167(167) 98(81) \quad 44(51)$ \\
\hline & Dorsa! & 35.7 & 25.15 & 1.848 & -0.9529 & 0.04936 & 0.9946 & $62(61) 87(88) 106(108) \quad 118(116) \quad 119(144) 111(111) \quad 94(102) \quad 70(70) 40(35) 13(15)$ \\
\hline & Ventral & $7 \% .0$ & 134.9 & 13.233 & -3.2140 & 0.17026 & 0.9869 & $96\{91) \quad 130(140) \quad 159(156) \quad 175(172) \quad 175(170) \quad 156(155) \quad 122(132) \quad 87(85) \quad 40(35) \quad 19(15\rangle$ \\
\hline \multirow[t]{3}{*}{342} & Overall & 92.2 & 612.5 & 5.693 & -2.7343 & 0.14835 & 0.9947 & 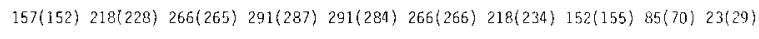 \\
\hline & Lorsal & 39.0 & 40.98 & -0.618 & 1.0280 & 0.06671 & 0.9993 & $78(77) \quad 111\{117) \quad 134(132) \quad 144(140) \quad 142(137) \quad 127(132) \quad 103(108\} \quad 74\{74) \quad 46(62) \quad 2 \varepsilon(27)$ \\
\hline & Ventral & 56.0 & 30.48 & 6.035 & -2.3592 & 0.14190 & 0.9931 & 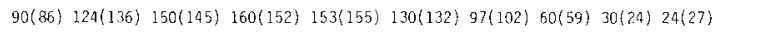 \\
\hline \multirow[t]{3}{*}{372} & Qveral1 & 257.5 & -93.117 & 18.724 & -1.99027 & 0.079865 & 0.9981 & $168(163) 247(253) 285(277) 297(292) \quad 292\{292) 270(263) \quad 212(210) 134(133) 68(66) 57(54\}$ \\
\hline & Dorsal & 50.6 & 46.12 & -9.149 & 0.6891 & -0.02695 & 0.9893 & $88(87) 111(114) 123(125) 126(126) 122(117) 112(111) 97(104) \quad 76(84) \quad 50(40) \quad 18\{22)$ \\
\hline & Ventral & 66.8 & 25.71 & 5.286 & $-1,8355$ & 0.099942 & 0.9829 & 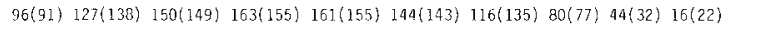 \\
\hline 460 & Overali & 116.4 & -4.5 & -1.0387 & 0.06739 & 0.06789 & 0.9075 & 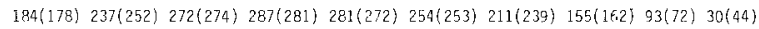 \\
\hline
\end{tabular}

In figures $1-3$ the body and finlet profiles are shown side by side. Heights of the body outline above and its depth below a line joining snout tip to middle of caudal peduncle at hypural joint taken as 10 equal intervals are shown in table 1 . To obtain 10 comparable entries from 7 or 8 finlets the measured heights have been plotted against abscissae marked off in intervals proportional to distances between individual finlets, and ordinates measured from the graph for 10 equidistant abscissae; these values then being arbitrarily scaled up (by a factor of 6) to make the finlet curve of the same order of magnitude as the body curve. It is seen the two curves exhibit considerable resemblance, with the anterior portions more or less parallel, but the posterior portions divaricating backward.

In figures 4-6 the ordinates of the finlet deciles are plotted against the body deciles. To obtain these 10 comparable entries from 7 or 8 finlets the measured heights were plotted against abscissae marked off at intervals proportional to distances between individual finlets (as in figs 1-3), and ordinates measured from the graph for 10 equidistant abscissae. Deciles $\{1-4\}$ and $\{6-9\}$ show a strong tendency to be linear; with deciles 5, 10 less constant in position. Of the $\{12-1\}$ such lines (Falmouth dorsa1) decile set $\{1-4\}$ with only 2 variates) 1 only fails to yield a formally significant correlation (West Coast $\{6-9\}$ with $r 0.712, z 0.891) 4$ of the remainder being significant at levels better than 5\%, 6 at better than $1 \%$; mean values for dorsal finlets (two 4-member sets pooled) $r 0.993$ ( $z 2.811$ ) for anal finlets 0.939 (1.727). The relevant data are set out in table 2. It may be noted the correlation noted earlier for the Mersey specimen was that between the anterior 4 and posterior 4 of the 8 finlets with the anterior 4 and posterior 4 of the 10 body measurements; not, as here, between the latter and the anterior 4 and posterior 4 of the decile finlet heights derived from the curves in figs $4-6$ 
E.O.G. Scott

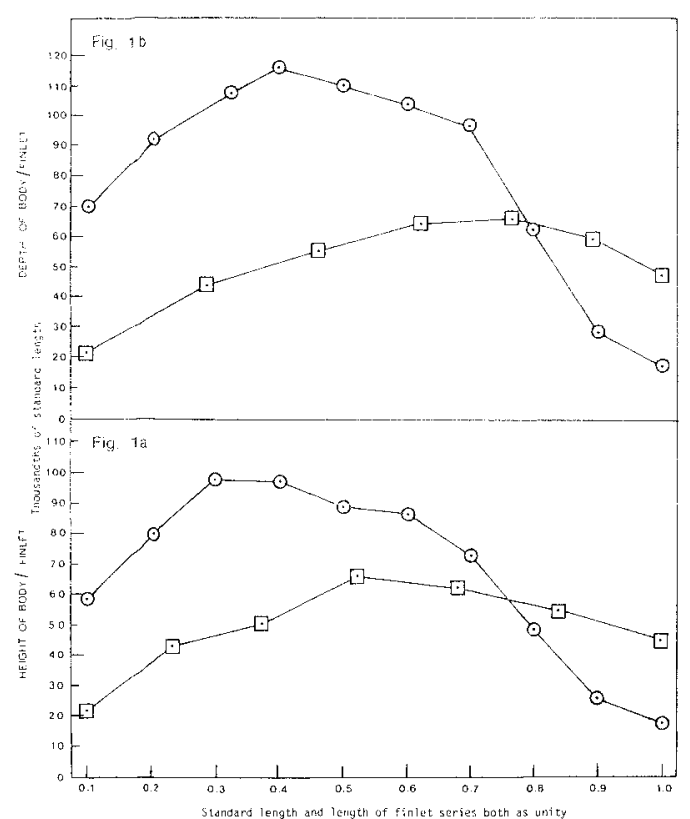

FIG. 1 - Gasterochisma meLampus Richardson, 1845. a: Height of dorsal profile above a mediolateral anteroposterior axis, and height of dorsal finlets. b: Depth of ventral profile below same axis, and height of anal finlets. All dimensions as thousandths of standard length; profiles circles, finlets squares. Specimen standard length $234 \mathrm{~mm}$, from west coast, lasmania.

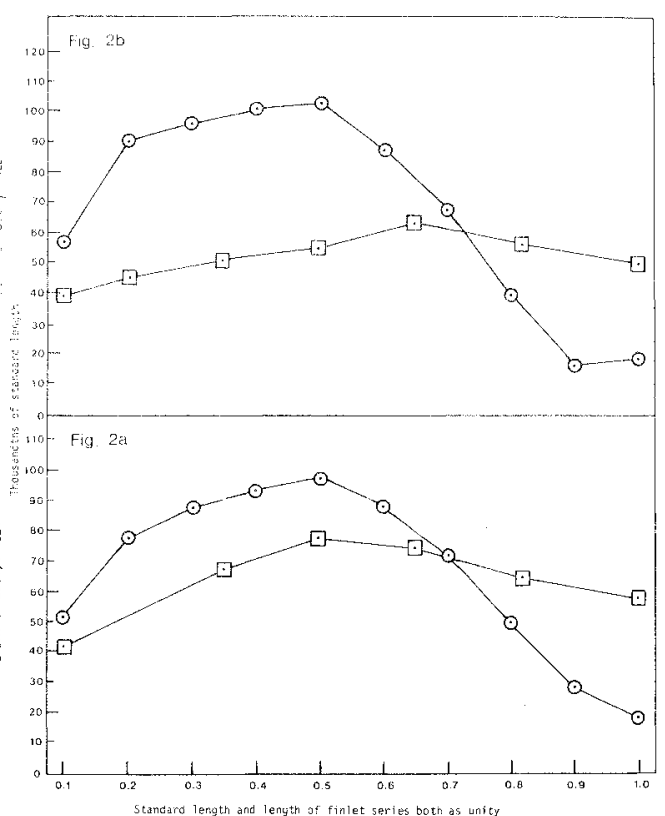

FIG. 2 - Gasterochisma mezampus Richardson, 1845. a: Height of dorsal profile above a mediolateral anteroposterior axis, and height of dorsal finlets. b: Depth of ventral profile below same axis, and height of anal finlets. All dimensions as thousandths of standard length; profiles circles, finlets squares. Specimen standard length $372 \mathrm{~mm}$, from Falmouth, east coast, Tasmania.

\section{Individual variation in body form}

Measurements of height of body above and depth below an anteroposterior axis from snout tip to middle of caudal peduncle at 10 equal intervals have been made on our four specimens (including the Mersey example reported on earlier). These dimensions, as thousandths of standard length, are shown in table 1 , where they are fitted with $4^{\circ}$ polynomials.

Individual variations may be further examined by comparisons of the sums of the decile heights and depths of the anterior and posterior halves of the dorsal profile, the ventral profile and the overall outline. In all save 1 of the 27 subsets the relative heights and depths of the smallest exceed those of the other specimens. In the largest individual but one the anterior portion of the dorsal profile is lower, while the posterior portion is higher, than in the rest. Individual differences of the local dimensions can result in other appreciable differences in general appearance. Thus for the ratio anterior half/posterior half of the dorsal profile the value for the Falmouth individual is decidedly less than values for the others while for the same ratio for the ventral profile is the highest. The Mersey individual is lower than the rest in the region of the first two deciles also in the region of the last two deciles; further, the total for the 10 dorsal measurements is the lowest. The caudal peduncle region exhibits noticeable variation, the penultimate measurement in seven instances being $1.5-2.3, \bar{x} 1.8$ times the last, but in one instance only 0.9 of it. 


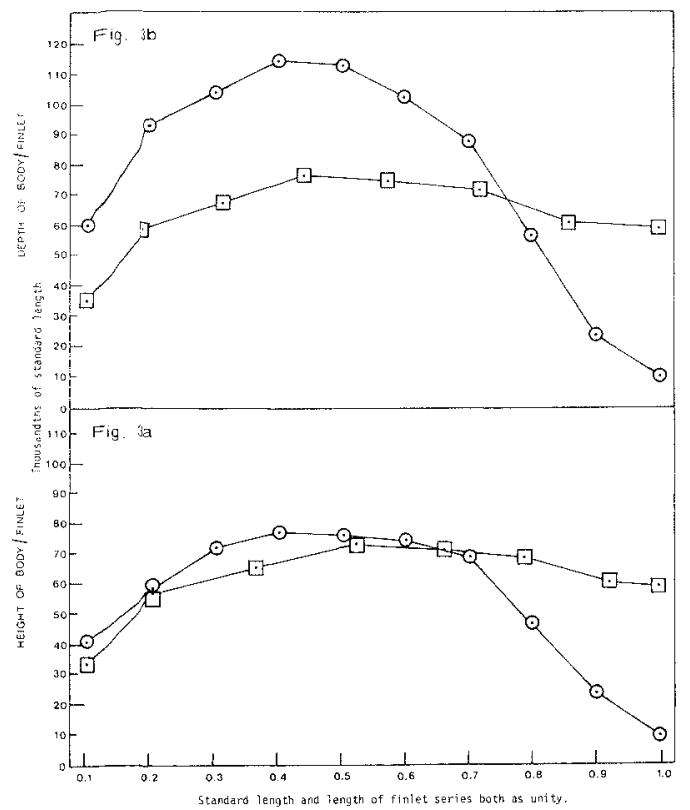

FIG. 3 - Gasterochisma me Lampus Richardson, 1845. a: Height of dorsal profile above a mediolateral anteroposterior axis, and height of dorsal finlets. b: Depth of ventral profile below same axis, and height of ana 1 finlets. All dimensions as thousandths of standard length; profiles circles, finlets squares. Specimen standard length $342 \mathrm{~mm}$, from off Mersey River, northwest coast, Tasmania.

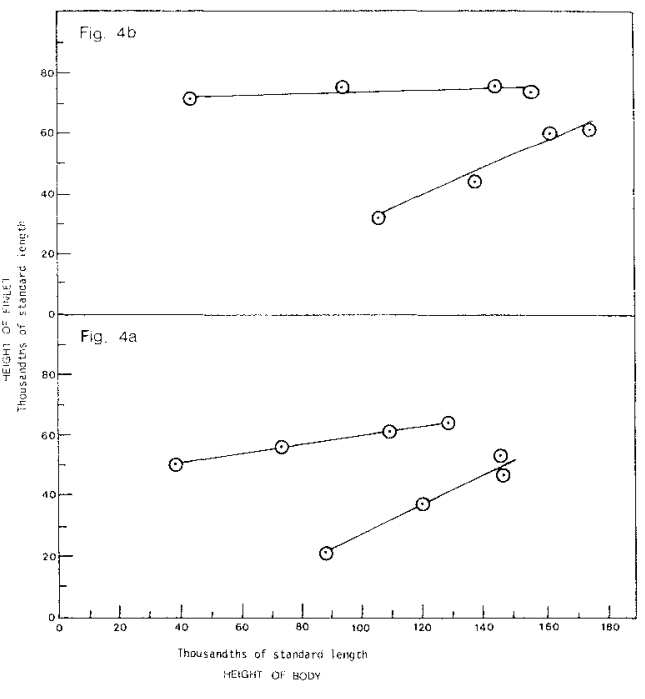

FIG. 4 - Gasterochisma me Zampus Richardson, 1845. a: Height of dorsal finlets, read off as deciles from fig. la, plotted against decile heights of dorsal profile above a mediolateral anteroposterior axis $\mathrm{b}$ : Height of anal finlets, read off as deciles from fig. $1 \mathrm{~b}$, plotted against decile depths of ventral profile below same axis. Specimen standard length $234 \mathrm{~mm}$, from west coast, Tasmania.

Within the range of the sample, in the dorsal profile the anterior half is markedly more variable than the posterior $(V 18.7,5.9)$, while in the ventral profile the reverse obtains $(V 12.2,6.3)$. With dorsal and ventral profiles combined the anterior portion is about half as variable again as the posterior $(V 9.6,6.0)$.

\section{General features}

Some general features subject to individual variation are here specified for the West coast fish. D. XVII; I, 9 (last two rays finlet-like); 7 finlets. A.I, 10 (hinder rays increasingly finlet-like); 7 finlets. P. I, 20. C. 6/24/7. L.1. ca 54, terminating on right side below last one-sixth of anal base, on left below first finlet. L. tr. $8+$ ca 19. Operculum smooth; several obscure scales near upper border. Preoperculum fully scaled; 6 rows beneath eye. Scales on occiput ceasing above first two-fifths of eye on left side, about first one-tenth on right. No distinct corselet, but about 5 rows of scales below pectoral base larger than adjacent scales. Some 8-9 rows of scales behind operculum above pectoral base sloping obliquely forward and upward. No definite peduncular keel: two raised lines extending forward for nearly a head length from level of last finlet (possibly post-mortem). Maxilla to below middle of eye. 


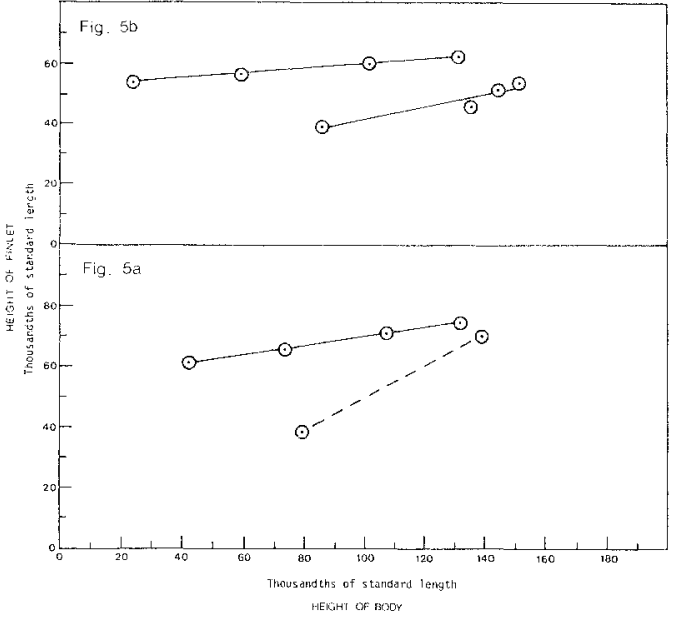

FIG. 5 - Gasterochisma melampus Richardson, 1845. a: Height of dorsal finlets, read off as deciles from fig.2a, plotted against decile heights of dorsal profile above a mediolateral anteroposterior axis. $b$ : Height of anal finlets, read off as deciles from fig. $2 b$, plotted against decile depths of ventral profile below same axis. Specimen standard length $372 \mathrm{~mm}$, from Falmouth, east coast, Tasmania.

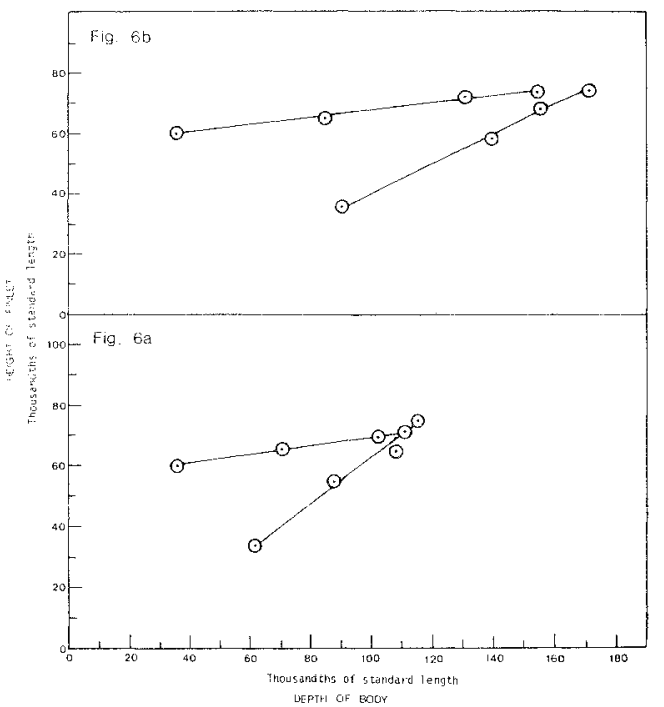

FIG. 6 - Gasterochisma melampus Richardson, 1845. a: Hieight of drosal finlets, read off as deciles from fig.3a, plotted against decile heights of dorsal profile above a mediolateral anteroposterior axis. $\mathrm{b}$ : Height of anal finlets, read of as deciles from fig.3b, plotted against decile depths of ventral profile below same axis. Specimen standard length $342 \mathrm{mn}$, from off Mersey River, northwest coast, Tasmania.

\section{Coloration}

Trunk and tail plumbeous above midlateral line, more or less silvery below. Head mainly like trunk, but naked portion mostly more or less flesh-colored, blackish on dorsum of snout. First dorsal translucent, colorless or faintly yellowish; second dorsal and anal with a very dark brownish streak covering proximal half or two-thirds of each ray, pale yellowish. Dorsal and anal finlets mostly yellowish, with small anterior proximal patch of melanin pigmentation breaking up distally into diffuse chromatophores. Pectoral pale greenish yellow, rays darker. Ventral black or blackish. 
Three Australian species are commonly accomodated in this small family: (a) Fseuciaphitis bursinus (Cuvier, 1830), appearing in most of the recent local texts as 2. Wrilizi (valenciemes, 1831); (b) Bovichtus variegatus Richardson, 1846; (c) Bovichtus angustifrons Regan, 1913, the validity of which would seem to be open to some doubt. Though (a) was originally associated by McCulloch (1922) with (b) and (c), later in the Check-List (1929) he placed it in the monotypic fanily Pseudaphritidae: earlier writers had referred these two genera to Trachinidae (Günther 1880 , Johnston 1883, 1891) or to Nototheniidae (Boulenger 1910). All three species occur in Tasmania, which provides the locality for one of the two specimens on which (c) was based (source of other unknown); while this State, fide McCulloch (1929), is the type locality of P. urvizziz.

Subsequently to the emendation by Agassiz (1845) of the name of the type genus Bovichtus Valenciennes, 1831 to Bovichthys the familu name has assumed several variant forms (at times - c.g. Lord and Scott (1924). more than one in the same publication) including Bovictidae, Bovichtidae, Bovicthidae, Bovichthyidae, the last-named receiving the imprimatur of Greenwood et al. (1966) in their provisional classification of living teleosts. A key to the Tasmanian members of the family appears in Part VI (1953), which provides some meristic and morphometric data on a sample of juveniles of Bovictus variegatus, further notes on this species being given in Part VIII (1957); observations on Pseudophritis bursinus (as P. urviltii) are reported and discussed in Part IX (1960).

\section{Genus PSEUDAPHRITIS Castelnau, 1872}

Pseudaphritis Castelnau, 1872, p.92. Type-species, Pseudaphritis bassii Castelnau, $1872=$ Eleginus bursinus Cuvier, 1830 .

Arhmitis Valenciennes, 1831, p.483. Tyep-species, Aphritis urvilzii valenciennes, $1831=$ EZeginus bursinus Cuvier, 1830. Preoccupicd by Aphritis Latreille, 1804 (Diptera).

Phricus Berg, 1895, p.65 (substitute name for Aphritis Valenciennes, 1831; preoccupied as above).

\section{Pseudaphritis bursinus (Cuvier, 1830)}

$$
\text { (Text-figs 7-9) }
$$

Eteginus bursinus Cuvier, 1830, p.161. Type locality: Port Jackson (Quoy \& Gaimard).

Aphritis urvilzii valenciennes, 1831, p.484, p1.243. No locality (D'Urville) [= Tasmania, fide McCulloch 1929, p.337].

Aphritis urvilzi: Al1port, prior to 1882 (MS): Johnston, 1883, p.116.

Uphritis urvilzit: Johnston, 1891, pp.25,33 (reprint, 1891, pp.4,12).

?Elleginus bursinus: Ogilby, 1898, p.560: McCulloch, 1929, p.337 (in synon.).

Pseudaphritis bursinus: Scott, 1962, p.238: Whitley, 1964, p.53.

Eseudaphritis bassiz Castelnau, 1872, p.92 (in specific diagnosis, p.92, second binomen rendered bassï, typographical error for bassii; correctly rendered in index to paper, p.240). Type locality: the Straits of Bass [now Bass Strait].

Fseudaphritis bassii: Macleay, 1881b, p.565: Lucas, 1890, p.26: McCul1och, 1929, p.337 (in synon.; p.72 in Castelnau cited in error for 92).

Aphritis bassi: Ogilby, 1890, p.68.

Aphritis dumerili Günther, 1874, p.91 [Based on Pseudaphritis bassii Castelnau, 1872 dumerili presumably a lapsus ealami for churvili, an erroneous version of urviltii Valenciennes, 1831, used elsewhere by Günther (1861, Ann. Mag. nat. Hist., 3(7), p. 88)].

Pseudaphritis urvitzii: Macleay, 1881, p.565: Ogilby, 1898, p.560: Hale, 1920, p.25: Waite, 1921, p.141, fig.221 and 1923, p.164, unnumbered fig. and 1924, p.482, pl.30, fig.1: McCulloch, 1922, p.103, p1.47, fig.283a and 1927, p.77, p1.32, fig.283a, and 1929, p.337: Lord, 1927, p.15: Lord and Scott, 1924, pp.12,78: Scott, 1960, p.92: Scott, Clover and Southcott, 1974, p.267, unnumbered fig.: Andrews in: McDowall 1980 , p.167, fig.30.1.

Pseudaphritis urvizi: Lord, 1923, p.69. 
E.0.G. Scott

Note on second binomen

As is evident from the above tabie of synonymy, apart from what may be regarded as minor eddies such as those associated with Castelnau's bassii, the general current of Australian taxonomy (in which a paper (1960) by the writer joined) has accepted as the second binomen for this fish the 1831 wrvizliz of valonciennes; and this identifjcation persists in the latest text (Andrews, in: McDowall 1980). However, near the end of the last century ogilby (1898), who had earlier (1890) given a redescription of Castelnau's $P$. bassii (emending bassiz to bassi), observed at the conclusion of a detailed review of the history of Aphritis, Psendaphmtis and allied genera, "Tf the suggestion here made that Zliginus bursinus [footnote gives reference to "Cuvier q valenciennes", 1830 - the relevant volume, 5 , is by Cuvier] is identical with Aphritis urvizzii, be correct, our fish will have to be called Pseudaphritis bursinus. E. bursinus was said to have been collected by Quoy and Gaimard in Port Jackson during their first voyage to the southern hemisphere in the Uranie; it has not since been recognized."

While the Check-Jist (Mchulloch 1929) obviously included an entry "isteginus bursinus" (McCulloch has clearly been earlier exercised by the problem, leading him in his catalogue of New South Wales fishes and fish-like animals (1922) to take the step, unusual in that work, of expressly noting an unresolved taxon), the recognition of urvizz: remained the rule, and even the exceptional adoption by scott (1962) in his catalogue of South Australian fishes of bursinus was negated in the second edition of the work (1974; in collaboration with Glover and southcott). However, bursinus has been accorded formal status by whitley in his definitive name-list of fishes recorded from Australia (1964). In the century and a half since the description by Cuvier of Ezeginus bursinus from Port Jackson it would appear no fish referable to it other than the present fish has been reported, and despite some discrepancies in the reported fin counts there seems a high degree of probability that valenciennes' Aphmitis upviztii is a junior synonym of it: this view is adopted here.

\section{Vernacular name}

The book name Congolli, which has also some general currency in the southern mainland States, remains a purely formal designation in Tasmania, where the two names in actual common use are those given in our state lists from the earliest of these onward, namely, Sandy, Freshwater Flathead.

\section{Material}

In March and April 1981 the internation organisation Earthwatch and the Queen Victoria Museum, Launceston jointly conducted three expeditions to a little known part of the western coast of Tasmania, with base camp at Brooks Creek $29 \mathrm{~km}$ south of the Arthur River. Among the fish material collected and now deposited in the Museum was the following series of 15 specimens of Pseudaphritis bursinus: (a), (b), Ls 117.5,117, Smiths Gulch collected 23/03/81 \pm 7 days, Q.V.M. Reg. No. 1981/5/22; (c), Ls 71, Brooks Creek, $23 / 03 / 81$ \pm 7 days, Reg. No. 1981/5/23; (d) - (h), Ls $67,66,60.5,49,44,07 / 03 / 81 \pm 7$ days, Reg. No. 1981/ $5 / 12$; (i) -(o), Ls $179.5,169,144,154,104.5,70,56$, Broots Creek, 18/04/81 \pm 7 days, Reg. No. $1981 / 5 / 30$.

Material previously in the Museum's collections that has also been examined comprises: (ma), (mb), Ls 185, 255, no locality, Reg. No. 871b; (mc), (md), Ls 140, 147, Denison River at Wyena, Reg. No. 1957/5/3; (me), Ls 187, Gawler River at Ulverstone, 1955/5/6; (mf), Ls 265, Tamar River at Beauty Point, 1967/5/17; (mg), Ls 146, Welcome River, 1972/5/313; (mh), (mi), Ls 108,102 Stony Creek, West Tamar, 1976/5/62; (mj) Strahan, West coast, Ls 64, 1969/7/61; (mk), Ls 61, Ringarooma River, 1976/5/165; (m1), Ls 117, mouth of Ringarooma River, 1974/5/40; (mm), Ls 205, Bridport, 1974/5/40; (mn) Gawler River, Ls 115, 1979/5/47; (mo)-(ms), Gawler River, Ls 120,114,108.5,103,103, 1978/5/29; (mt) North Esk at St Leonards, Ls 187, 1957/5/8; (mu), North Esk at Killafaddy, Ls 127, 1953/5/1; (mv) (mw), Ls 162,154, St Helens, 1955/5/1; (mx), (my), Ls 103,99.5, 5 miles (8 km) west of Tomahawk, $1962 / 5 / 9$. 
Scope of inquiry

The expeditions' material has been studied somewhat intensively, with special reference to body form, differential growth, relative lengths of head trunk tail, location of vertical fins, lengths of rays and spine of ventral as functions of their serial numbers and of general body form, coloration, while the material previously in the Museum's collections has yielded some additional data relating principaly to meristic characters and proportions.

\section{Meristic characters}

The most recent treatment of the species (Andrews in: NeDowall 1980) gives the formulae for the vertical fins as D. VII-VIII, 19-22, A. II, 21-22: however, a total of 25 radjal elements in the anal is accepted in the local catalogues of Johnston (1883, 1891), and Lord and Scott (1924) and is depicted in the original figure (Cuvier 1830, pl.243 - reproduced in Waite (1921, fig.221, 1923, unnumbered fig.) and in McCulloch (1922, pl.47, fig.283a) - and in the replacement figure of Waite (1924, p1.30, fig.1). No counts transgressing these limits were encountered in our material. Apart from a range of $17-18$ reported in Part IX (1960) the pectoral is regularly described and depicted as consisting of 18 rays (Castelnau 1872, Ogilby 1890, Waite 1924, Scott 1962, Scott et al. 1974, Andrews in: McDowall 1980): in the Earthwatch material we count in 30 fins (17(7), 18(16), $19(7)$. V. 1, 5. The caudal count is conventionally 14; however, in some cases only 12 rays can be satisfactorily identified as main rays. A synoptic range by Andrews, taking account of all published accounts, sets the lateral line scales at 59-65: the Earthwatch sample yields $59(1), 60(3), 61(1), 62(5), 64(1), 65(2), 66(2)$, the last entry thus extending the limit upward. No reference appears to be made in local texts, apart from an observation in Part IX (1960), to the continuation of specialized scales beyond the hypural joint on to the caudal base, it being noted in that contribution that in the two fish examined there were 7,10 tubules extending for nearly half the length of the caudal fin: in the present sample there are $2(2), 3(3), 4(2), 5(2), 6(1), 7(3), 8(1), 10(1)$ posthypural tubules. For 1 . tr., given by Castelnau as 6/14, by Ogilby as 6/15, we find $5-8$ (modally 6)/14-18 (modally 15 or 16$)$.

Dimensions

A comprehensive set of 41 measurements of the 15 Earthwatch specimens is specified in Table 3, data for each dimension comprising range, mean, standard deviation, coefficient of variation, al1 dimensions other than standard length (which is recorded in mm) being given as millesimals of standard length. Measurements of individual specimens are recorded in Appendix No. II.

Measurements of standard length, total length, length to vent, length of head, length of pectoral, length of ventral, maximum depth, depth of caudal peduncle made for the 25 specimens constituting the earlier material in the Queen Victoria Museum's collections are recorded in Appendix No. III.

Proportions

The present paragraph notes 11 body ratios as exhibited by the 15 individuals of the Earthwatch series, each proportion being specified by range, mean with standard error, standard deviation, coefficient of variation, in that order. Head in standard length $3.0-$ $3.8,3.43 \pm 0.0590,0.229,6.7$. Maximum depth in standard length 5.6-5.7,6.46 \pm 0.131 , $0.506,7.8$ Depth of caudal peduncle in head 3.1-4.3,3.54 $0.0885,0.342,9.7$. Length to vent in standard length $1.8-2.5,2.14 \pm 0.0476,0.184,8.6$. Eye in head 4.3-6.7, 5.3 $\pm 0.216,0.835,15.9$. Eye in snout $0.9-2.0,1.21 \pm 0.0850,0.329,27.1$. Interorbital in eye $1.1-2.2,1.67 \pm 0.0969,0.375,22.5$. Snout in head $3.2-5.1,4.42 \pm 0.132,0.512,11.6$. Pectora1, measured from anterior border of root beneath operculum, in head 0.9-1.2, 1.05 $\pm 0.0200,0.0774,7.3$ : length of median pectoral ray in head 1.2-1.6, 1.43 $\pm 0.0408,0.141$, 9.8. Length of ventral in head $1.1-1.8,1.43 \pm 0.0552,0.214,15.0$. Length to first dorsal origin in standard length $2.2-3.1,2.74 \pm 0.0684,0.265,9.6$. Length to second dorsal. origin in standard length $1.8-2.1,1.95 \pm 0.0186,0.0719,3.7$. 


\section{E.O.G. Scott}

TABLE 3

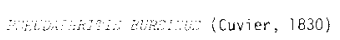

Diflensions of 15 specimens, standard length 44-179.5 anl, collected by a joint Earthwatch-Museuna Expedition to the "est Coast of Tasmania in March and April 1981: range, mean, standard deviation and coefficient of variation. First line of table, standard length, in miblimetres, all other 7 ine as thousandths of standard length.

\begin{tabular}{|c|c|c|c|c|}
\hline Feature & Raninge & $\bar{x}$ & $\therefore$ & 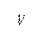 \\
\hline Standard length, $\mathrm{mm}$ & $44-179.5$ & 96.0 & 43.44 & 45.2 \\
\hline Total length & $1134-1390$ & 1206.2 & 61.80 & 5.1 \\
\hline Length to first dorsal origin & $325-462$ & 368.1 & 39.10 & 10.6 \\
\hline Length to first dorsal termination & $388-529$ & 455.7 & 42.23 & 9.3 \\
\hline Length to second dorsal origin & $490-612$ & 533.4 & 33.75 & 6.3 \\
\hline Length to second dorsal termination & $838-925$ & 889.0 & 24.01 & 2.7 \\
\hline Length to anal origin & $430-562$ & 496.6 & 36.36 & 7.3 \\
\hline Length to anal tenuination & $852-982$ & 904.7 & 36.02 & 3.0 \\
\hline Length to vert: & $394-546$ & 470.1 & 39.68 & 3.4 \\
\hline Length to pectoral origin & $182-279$ & 216.2 & 28.28 & 13.1 \\
\hline Length of pectoral & $231-306$ & 278.5 & 24.04 & 8.6 \\
\hline Length to ventral origin & $159-276$ & 223.2 & 30.36 & 13.6 \\
\hline Length of ventral & $156-269$ & 208.9 & 33.55 & 16.1 \\
\hline Head & $261-330$ & 292.7 & 19.07 & 6.5 \\
\hline Length to preopercular border & $143-229$ & 183.3 & 20.74 & 11.3 \\
\hline Snout & $55-95$ & 67.0 & 11.33 & 16.9 \\
\hline Eye & $47-70$ & 56.7 & 7.55 & 13.5 \\
\hline Interorbital & $28-43$ & 33.1 & 5.15 & 15.2 \\
\hline Length of maxilla & $64-107$ & 79.4 & 14.15 & 17.9 \\
\hline Length to origin of upper caudal lobe & $932-1000$ & 965.7 & 24.13 & 2.5 \\
\hline Length to origin of lower caudal lobe & $910-1000$ & 952.9 & 27.20 & 2.9 \\
\hline Deptin at front of eye & $61-100$ & 91.3 & 11.44 & 14.1 \\
\hline Depth at back of eye & $89-148$ & 106.3 & 16.3 & 15.4 \\
\hline Gepth at opercul um & $127-165$ & 144.8 & 11.85 & 8.2 \\
\hline Depth at first dorsal origin & $132-170$ & 152.5 & 12.84 & 8.4 \\
\hline Depth at first dorsal termination & $138-169$ & 153.3 & 10.18 & 6.6 \\
\hline Depth at second dorsal origin & $141-164$ & 153.5 & 7.27 & 4.7 \\
\hline Depth at vent & $134-172$ & 153.9 & 11.42 & 7.4 \\
\hline Depth at anal origin & $139-169$ & 351.9 & 10.20 & 6.7 \\
\hline Depth at second dorsal termination & $82-104$ & 89.5 & 8.05 & 9.0 \\
\hline Depth at anal termination & $63-96$ & 79.2 & 8.03 & 10.1 \\
\hline Maxinium depth & $134-180$ & 155.7 & 12.24 & 7.9 \\
\hline Depth of caudal peduncle & $75-93$ & 83.1 & 67.56 & $a .1$ \\
\hline Width at first dorsal origin & $105-170$ & 139.8 & 19.85 & 14.2 \\
\hline Width at first dorsal temingation & $101-16$ in & 135.9 & 20.51 & 15.1 \\
\hline Width at second dorsial origgin & $94-15 ?$ & 127.1 & 19.84 & 15.6 \\
\hline width at vent & $105-155$ & 133.0 & 17.33 & 13.2 \\
\hline Windth at anal origin & $49-155$ & 128.6 & 20.36 & 15.8 \\
\hline Width at second dorsal tersination & $32-68$ & 47.4 & 11.72 & 24.7 \\
\hline Width st antal tennination & $29-60$ & 42.5 & 10.60 & 25.2 \\
\hline
\end{tabular}


Among the above ratios positive correlation with ts at better than $\mathrm{p} 0.01$ is exhibited by eye in head $(r 0.955, z 1.887)$, eye in snout $(r 0.929, z 1.655)$, caudal peduncle depth in head $(r 0.842, z 1.229)$. Negative correlation with $2 s$ at better than $p 0.01$ is exhibited by maximum depth in standard length $(r-0.799, z-1.097)$, snout in head $(r-0.709$, z -0.884$)$, length to first dorsal origin in standard length $(r-0.884$, $z-1.393)$. It is of interest to note that with overall growth relative maximum depth and relative depth at caudal peduncle tend to vary in opposite senses.

Some similar ratios derived from the less extensive series of measurements made of the larger sample of the earlier Museum material, which exhibit some interesting variations, are recorded in Appendix No. IV.

\section{Size}

The range in standard length of the 15 Earthwatch specimens is 44-179.5 mm, in total length 53.2-215.5; the ranges for the 25 original Museum examples 61-265, 77-306. Some assessments of the maximum size attained by this species: 14 inches [356 mon] Waite 1921), 12 inches [305 mu] (McCulloch 1922), $250 \mathrm{~mm}$ (Lord and Scott 1924), 360 $\mathrm{mm}$ (Scott et al. 1974), "examples up to $300 \mathrm{~mm}$ known but usual size around $150-200$ mm" (Andrews in: McDowal1 1980). Of his material of Eleginus bursinus Cuvier noted "Notre plus grand individu n'a que six pouces."

\section{Size classes}

Nothing appears to be known of the growth rate. A provisional classification of the Earthwatch sample of 15 individuals would suggest the recognition of three size (age?) groups: (a) 8 specimens, Ls 44, 49, 56, 60.5, 66, 67, 70, 71, $\bar{x}$ 60.4; (b) 3, Ls 104.5, $117,117.5, \bar{x} 113.0$; (c) 4 , Ls 134, 144, 169, 179.5, $\bar{x} 156.6$. Support for this dissection is provided by the fact that in all save one (length to hind caudal margin) of the 12 length-to dimensions set out in table 4 as being functions of overall size there is found a consistent increase (or in last entry decrease) in magnitude for the variates (a) (b) (c) in that order (most other dimensions investigated follow the same sequence). The probable homogeneity of the accepted classes is further indicated by the sizes of the relevant coefficients of variation: for (a) $V=16.5$, (b) 6.5, (c) 13.5 ; while (a) + (b) and (b) + (c) yield decidedly higher values, $34.6,20.3$ (calculations with a.f. $n-1$ ).

\section{Differential growth along anteroposterior axis}

While consistency of the sequence $(a)>(b)>(c)$, or $(a)<(b)<(c)$, obtains, in respect of length-to measurements, it is not to be expected with such small samples that the interclass increments should exhibit quantitative regularity, and accordingly it has been deemed expedient in considering differential growth along the general anteroposterior axis of the fish to pool classes (b) and (c), giving subsample $A$ with 8 specimens of Is $49-71 \mathrm{~mm}$ and subsample $B$ with 7 of $L s$ 104.5-179.5.

It is found that at 11 of 12 selected sites on the axis the mean length to the point, assessed as a millesimal of standard length, in $B$ exceeds that in $A$, the change of sense occurring beyond the origins of the caudal ridges, somewhat in advance of the hypural joint. This growth gradient exhibits two segments: for the first three entries the mean value of $B$ as a percentage of that of $A$ decreases from 118.0 (at origin of pectoral) to 107.6 (at opercular margin); for the remaining entries, excluding the final entry for total length, it decreases from 115.2, (at first dorsa1 origin) to 100.2 (at mean of upper and lower caudal ridge origins). The data are set out in table 4 and the general nature of the gradient is shown graphically in fig.7. The decrease caudad is statistically significant in both segments.

Length of head, length to vent, standard length

It is found that in a $\log \log$ plot these three basic dimensions are linear, with high statistical significance, on $\{1,2,6\}$ (Appendix No. V). 
TALLE a

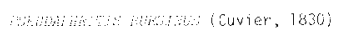

Relaty ve growth as indicated by lengths recorded as thousandths of standard length to selected points along anteroposterior axis in a pooled sample from the Hest Coast, rasmania: subsample a of 8 speciniens of standard 7ength $49-71560.4$ min, subsample $n$ of 7 of standard length $104.5-179.5 \bar{x} 137.9$ rmm. Estimates of 35 as percentage of $h$ derived fron two equations in the text.

\begin{tabular}{|c|c|c|c|c|c|c|c|c|c|}
\hline \multirow{2}{*}{\multicolumn{2}{|c|}{ Feature }} & \multicolumn{2}{|c|}{ Subsample Á } & \multicolumn{2}{|c|}{ Subs ample :s } & \multicolumn{2}{|c|}{ sas as percentage of $x$} & \multicolumn{2}{|c|}{ Total sample: correlation with in } \\
\hline & & Range & $\bar{x}$ & Range & $\bar{x}$ & Measured & Estimated & $n$ & $\because$ \\
\hline Length to: & arigin of pectoral & $182-2,29$ & 198.8 & $204-279$ & 234.4 & 118.0 & 118.9 & $0.838 * \star * t$ & 1.213 \\
\hline : & origin of ventral & $159-249$ & 205.3 & $222-276$ & 243.7 & 118.7 & 117.7 & $0.716 \star * *$ & 0.899 \\
\hline & opercular margin & $261-307$ & 282.6 & $285-330$ & 304.1 & $10 \% .6$ & 107.7 & $0.605^{*}$ & 0.701 \\
\hline & first dorsal origin & $325-364$ & 343.7 & $344-462$ & 396.0 & 115.2 & 116.3 & $0.304 * * *$ & 1.131 \\
\hline : & first dorsal temination & $338-457$ & 424.3 & $459-529$ & 491.6 & 115.9 & 112.3 & $0.782 * * *$ & 1.051 \\
\hline & vent & $394-500$ & 446.9 & $453-546$ & 496.6 & 111.1 & 111.4 & $0.597^{\star}$ & 0.688 \\
\hline : & anal origin & $455-523$ & 476.8 & $479-562$ & 519.3 & 108.9 & 110.4 & $0.523^{\star}$ & 0.581 \\
\hline : & second dorsal origin & $490-543$ & 522.0 & $526-612$ & 559.0 & 107.1 & 109.0 & 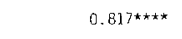 & 1.149 \\
\hline : & second dorsal temination & $838-941$ & 880.9 & $863-925$ & 920.4 & 104.5 & 103.4 & $0.539 *$ & 0.602 \\
\hline : & anal temrination & $852-916$ & 881.3 & $880-982$ & 931.6 & 105.7 & 103.4 & $0.570^{*}$ & 0.648 \\
\hline : & caudal ridge origins, mean & $915-1000$ & 955.9 & $910-985$ & $95 \% .8$ & 100.2 & 102.7 & 0.090 & 0.091 \\
\hline : & hind caudal nargitin & $1134-1243$ & 1213.0 & $1137-1243$ & 1198.4 & 98.8 & - & -0.263 & -0.281 \\
\hline
\end{tabular}

Location of dorsal fins relative to caudal base

In a $\log \log$ plot the length-to set length to origin, to termination of first dorsal, to origin, to termination of second dorsal, to origin of caudal (Ls) $\}$ is significantly linear on the integer set $\{3,4,5,9,10\}$ (Appendix No. VI).

Location of anal fin relative to caudal base

In a loglog plot the length to origin of ana 1 , to termination of ana 1 , to caudal origin (Ls) is significantly linear on the integers $\{3,8,10\}$ (Appendix No. VII).

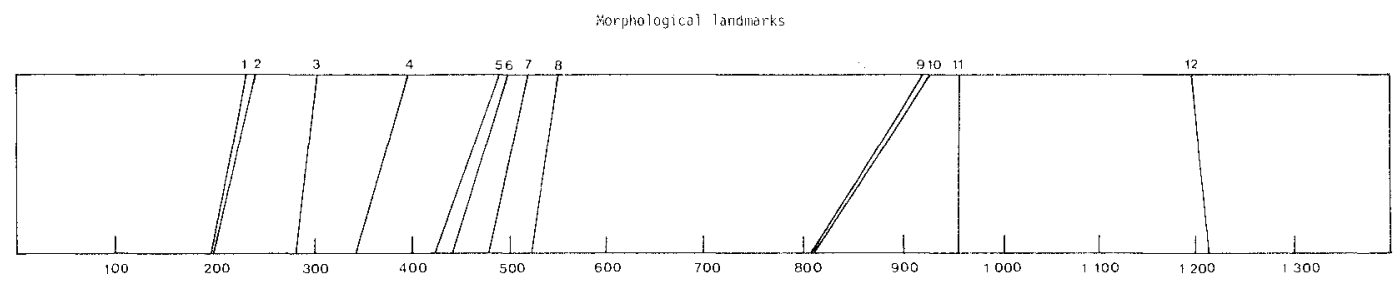

Thousandths of standaró length

FIG. 7 - Pseudaphritis bursinus (Cuvier, 1830). Relative growth as indicated by lengths to selected points in a sample from the west Coast, Tasmania. Lower line subsample A, 8 specimens, mean standard length $60.4 \mathrm{~mm}$; upper line subsample B, 7 specinens, mean standard length $137.9 \mathrm{~mm}$. Points of measurement: length to 1 pectoral origin, 2 ventral origin, 3 opercular margin, 4 first dorsal origin, 5 first dorsal termination, 6 vent, 7 anal origin, 8 second dorsal origin, 9 second dorsal termination, 10 anal termination, 11 caudal ridges origins (mean), 12 hind caudal margin. 
Ventral fin

Two interesting length patterns axe exhibited by the radial elements of this fin, one involving their lengths and their serial numbers, the other being a relation between their length and the depth of the fish at specified points along the general anteroposterior axis: these two patterns are discussed below. Following the convention adopted in Part XXI (1974) the ray furthest from the spine (most postaxial) is counted as the first; while the spine is here conveniently taken as being homologous with the soft rays and thus treated as the sixth radial element overall.

\section{Length-nunber pattern in ventral}

The radial elements exhibit a characteristic length-number pattern in two sets, the lengths of $\{1,2,3\}$ being linear, in a $\log \log$ plot, on their serial numbers and $\{6,5,4,3\}$ being linear, in a loglog plot, on $\{1,2,3,4\}$, respectively: it will be observed the sets intersect, with ray 3 the common member. The parameters of the equation $I=b i i^{k}$ rectified as $\log L=k \log N+\log b$, together with its statistical significance and the estimated and measured length, recorded as millesimals of standard length, for each of four indiriduals are set out in table 5. Calculations for some further specimens have been found to give similar results. (The present pattern is an unusual one; in that commonly encountered the lengths of rays $1,2,3,4$ are linear, in a $\log \log$ plot, on their serial numbers $1,2,3,4$; no special length-number relation for the spine and ray 5 being apparent). While im most instances the corresponding ray elements of the right and left fins are subequal in length, it is of interest to note that when such is not the case, as in specimen (1) (in which the first ray of the right is $11 \%$ longer than that of the left), nevertheless both fins are specifiable by the one equation, though with markedly different parameters (slope of right 1.9 that of left).

TAB́LÉ 5

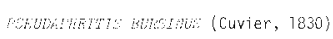

Length-number relations of ventral ray elements: $i=b i^{k}$ where $L=$ length of element, $n=$ a natural number; equation rectified in two sets, $L=\{$ ray $1,2,3 ; n=\{1,2,3 i, E=\{$ spine, rays $5,4,3\} n=\{1,2,3,4\}$. Lengths in millestmals of standard Tength, “L:

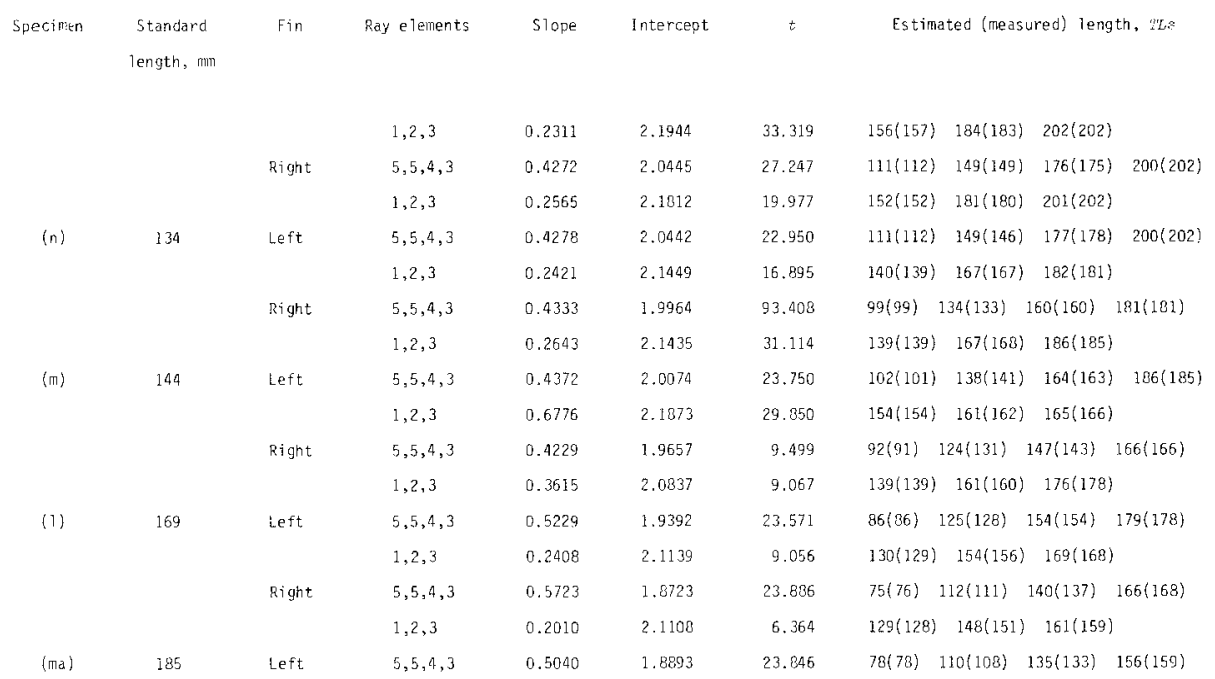


Ray lengths of ventral and body depth

When the lengths of the six ray elements are plotted against six equidistant measurements of the height of the dorsal profile above the anteroposteriox axis of the fish fron snout tip to middle of caudal peduncle at level of hypural (these heights being obtained either by direct measurement or in the case of the large individual from the Museum's old collection, (ma), by calculation from the equation for the profile recorded in Appendix No. VIII), it becomes evident one straight line results from joining the three points 2, 1, 6 and another from joining the four points 3, 4, 5, 6. Since the slopes of the lines for the two sets do not differ greatly - divergence most marked in ( $n$ ) - it is not inappropriate to calculate a single equation for the pooled set $\{1-6\}$, and this has been done (table 6). If measurements for the divergence of the ventral profile from the median anteroposterior axis of the fish are substituted as abscissal values for those for the divergence of the dorsal profile, a similar pattern is apparent for the same sets $\{2,1,6\}$ and $\{3,4,5,6\}$. However, while in two individuals, (1) and (ma), the slopes for these sets resemble those with the dorsal measurements as abscissae in being of tolerably similar magnitude, in the two other jndividuals they exhibit marked disparity (1.00, $2.07 ; 0.98,1.51)$ : accordingly data for the pooled set $\{1-6\}$ have not been recorded in the case of the ventral series.

TABLE 6

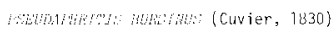

Lengths of the 6 ray elements of the pelvic ( $1=$ nost pastaxial ray, $6=$ spine) on 6 equidistant measurements of height of dorsal profite above and depth of ventral profile below an anteroposterior axis from tip of snout to middle of caudal peduncle at level of hypural joint: $L=m i s+c$, where $l,=$ ray element jength, $b$ = height or depth of hody as specified. All dimensions as millesimals of standard length.

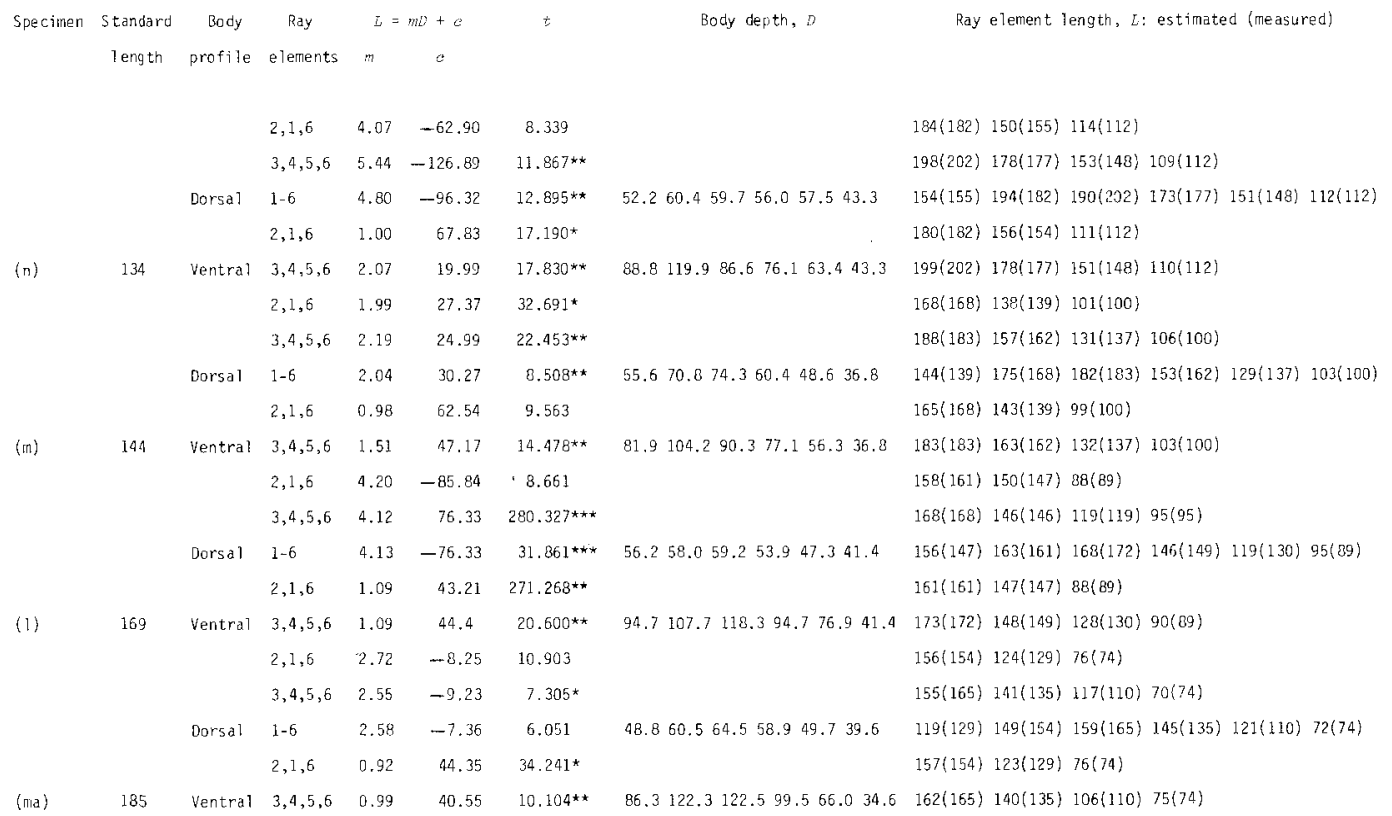


The parameters of the equation $L=m B+c(k=$ ray element length, $B$ = height or depth of body as specified above) for the material discussed in the preceding paragraph are exhibited in table 6 , together with height and depth measurements, estimated and measured lengths of ray elements (all dimensions as millesimals of standard length) and an indication of statistical significance. So far as the writer is aware a relation of this type subsistent between the form of the ventral fin (as specified by the lengths of its ray elements) and the body form of the fish has not previously been reported (certainly not for the present species). Unpublished information on some other species suggests profiles of other fins and body profiles may be specifiable each in terms of the othex. In Part XXVII (1981), it was shown that in the scombrid (3.2.) Gasterochisma melampus Richardson, 1845 the heights of dorsal and anal finlets are correlated with corresponding heights and depths of the dorsal and ventral body contours, a formulation confirmed for that species in the present contribution.

Dorsal and ventral profiles

Ten measurements at equa] intervals along an anteroposterior axis from the most advanced point of the snout to the middle of the caudal peduncle at the level of the hypural joint have been made of height, $H$, of fish above and depth, $D$, below this line for two large specimens in the original Museum collection, (ma) Ls 185 (mb) Ls 255 . In both fish the dorsal increases to a maximum at the fifth decile, the first five deciles accounting for $0.41,0.53$ of the total. In the ventral profile the maximum occurs at the fourth decile in the smaller fish but noticeably earlier, at the second, in the larger, the first five deciles representing slightly greater proportions of the total than in the dorsal profile, $0.59,0.58$. For the smaller specimen the sequence of magnitude of the deciles of height is $5>4=6>3>7>8>2>9>1>10$ : the same pattern occurs in the larger example save that here $6\langle 3$. For the depth deciles $4>3=5>6>2>7>$ $8>1=9>10$ and $2>3>4>5>6>1>7>8>9>10$.

Polynomials specifying the dorsal and ventral profiles as thus defined have been calculated (Appendix No. VIII).

Width

Widths at ten equal intervals have been measured for (ma) and (mb). Polynomial equations are recorded in Appendix No. IX.

The sequence of dccreasing magnitude of the deciles is in each case $3,4,2,5,6,1$, $7,8,9,10$, the largest being $1.3,1.6$ the first, $4.2,4.5$ the 1 ast, with the anterior five contributing $0.65,0.64$ of the total. Widths of the Earthwatch sample (together with depths) have been measured not at equal intervals but at a series of morphological 1 andmarks: means and ranges are recorded in table 4 (for individual measurements see Appendix No. III).

\section{Width as a function of depth}

A precise and interesting relation subsists between width and depth. With ten widths measured at equal intervals along standard length plotted against ten depths similarly measured, the two large well-preserved Museum specimens (ma) and (mb) yield the graphs shown in fig.8a, each presenting an upwardly convex curve for the early deciles and an upwardly concave curve for the later deciles. Each of the two segments of each graph represents a logarithmic arc such that $\log W=m D+c$, this linear relation (equations, Appendix No. $X$ ) being presented in fig. 8b. It may be noted that in (ma) the 1-3 are on extrapolation becomes continuous with the 4-10 are, yielding a sublenticular graph with a notable resemblance in overall form to a plot of fin borders on body profile encountered in an unpublished study of a scombrid (s.2.) Thunnis maceoyiz Castelnau, 1872. Thus the sampling of the situation with the grid employed (unit, one-tenth of standard length) is such that in the case of one specimen (ma) the point of change of the graph (from upwardly concave to upwardly convex) falls on the relevant length-decile (7th), while in (mb) it is missed by the grid measurement, merely occurring in its vicinity. 

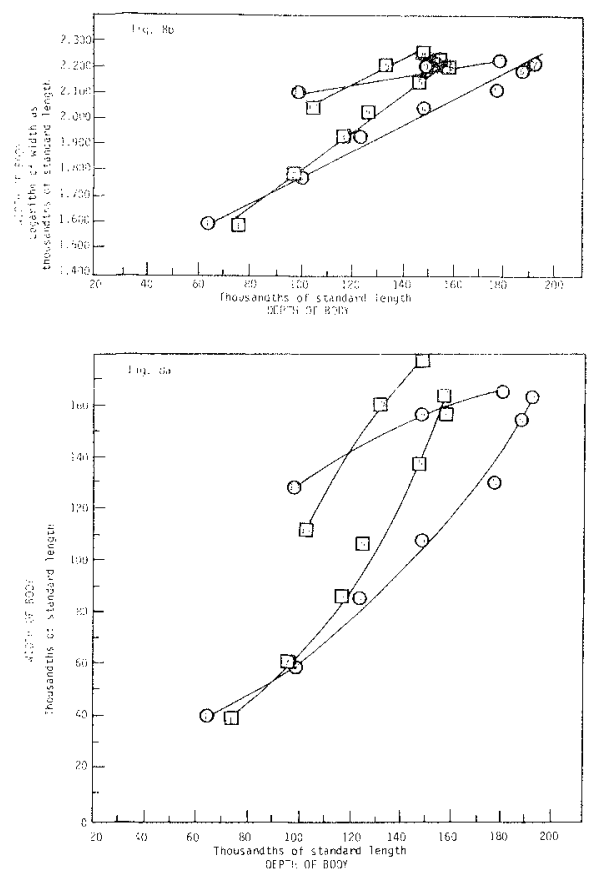

FIG. 8 - Pseudaphritis burginus (Cuvier, 1830). a: Sublenticular curve of width of body at 10 equidistant points on depth of body at 10 equidistant points: circle, specimen (ma), standard length $185 \mathrm{~mm}$; square, specimen (mb), standard length $255 \mathrm{~mm}$. b: Linear graphs of logarithms of these ares on depth of body: circle, (ma); square, (mb).
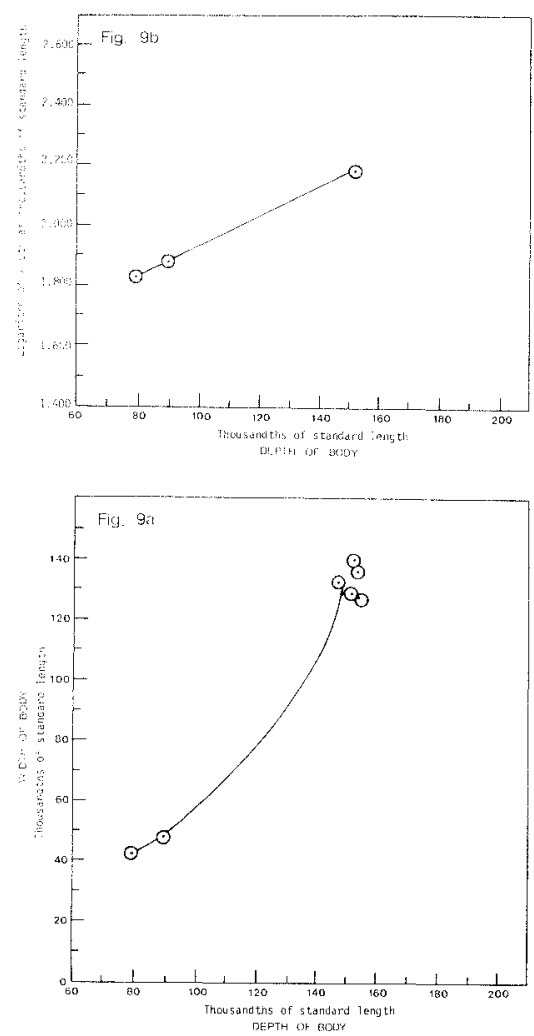

FIG. 9 - Pseudaphritis bursinus (Cuvier, 1830). a: Curve of width of body at certain morphological landmarks on depth of body at same points. b: Linear graph for logarithmic values of points $7,6,5$ on depth of body at same points. Landmarks: length to 1 first dorsal origin, 2 first dorsal termination, 3 second dorsal origin, 4 vent, 5 anal origin, 6 second dorsal termination, 7 anal termination. (Earthwatch material.)

Decile measurements of depth and width were not made for the Earthwatch 5 ample, but these dimensions were recorded at seven significant points along the general anteroposterior axis, namely, in sequence caudad, first dorsal origin, first dorsal termination, second dorsal origin, vent, anal origin, second dorsal termination, anal termination. The result of plotting mean width against mean depth for the 15 individuals is shown in fig. 9. The first four variates, located tolerably close together on $0.4-0.5$ of the standard length yield merely a clustcr of points: on the othor hand the three variates, anal origin, second dorsal termination, anal termination, which cover 0.5-0.9 of the standard length are capable of being joined to give an upwardly concave are similar to that noted above a joining the posterior decile measurements for the large specimens (ma) (mb). Like that arc it satisfies the relation $\log W=m D+c$ (Appendix No. $X$ ). 
Form as depicted in figures

Published figures raise several questions: none is wholly satisfactory. Those considered here are the original figure (Valenciennes 1831 , pl.243) of Aphmitis urvizlii based on the type material of that (synonymic) species, a substitute figure by Waite (1924, pl.30, fig.1) of a Tasmanian example $215 \mathrm{~mm}$ in length, a drawing in Andrews (in: McDowall 1980): in the subjoined comments these are designated $V, W, A$, respectively.

(a) Postdorsal membrane. In $V$ there is depicted behind the last spine of the dorsal a small unpigmented apparently delicate subtriangular membrane connecting it to the dorsum, i.ts horizontal subcqual to its vertical extent (in early Australian texts, e.g. Waite (1921, 1923) McCulloch (1922) this figure has fared so poorly in reproduction that this feature is barely visible, and was indeed earlier (1960) overlooked by the writer in these sources). In Part IX (1960: 93) it was reported that in two examples, Ls 75, 80.5, from George Bay, east coast, the first dorsal (but no other vertical fin) was broadly connected behind to the body by a membrane constituting $4.0 \mathrm{~mm}$ (subequal to eye) of a total base of 12.1. In an extensive series, collected over several months, from the North Esk, near Launceston, in which river, after an absence of two or three decades, this species suddenly appeared in abundance in 1957-58, a postdorsal membrane was regularly present. Such a membrane could readily be damaged or destroyed during collection and preservation. Examination of the Earthwatch material shows in several a small (? residual) area of membrane, in the majority a white fleshy strip adherent to the dorsum in the interdorsal region (probably interpretable as the remains of a membrane), in several no additional structure of any kind. No such membrane is represented in either $W$ or $A$, the dorsal ending sheerly at its last spine.

(b) Eye. In $V$ the eye just fails to reach the dorsal profile, in $W$ it is set somewhat lower, in A it projects markedly above the interorbital. Castelnau (1872, p.92) stated of his (synonymic) $P$. bassi "eye placed obliquely in the superior part of the head"; of the 1960 Tasmanian material it was noted "in strict lateral view, eye cuts profile"; Andrews observed, eyes "almost on top", "on top" of head. In the Earthwatch material the position in order of frequency is upper rim of orbit slightly above, just touching, moderately above, slightly below profile (no specimen as markedly projecting as in A).

(c) Lateral line. On the evidence afforded by the present material (and the 1960 specimens as described) the position of the lateral line is not satisfactorily depicted in any of the three illustrations, all of which place it, at least in some part of its course, too far below the dorsal profile. At first dorsal origin, second dorsal termination, origin of upper caudal ridge, origin of middle caudal rays its distance from the ventral profile is modally about $3-3.25$ (exceptionally 2.8), 3 (exceptionally 2.66), 2, 1.2 (to 1.5 ) times its distance from the dorsal profile: approximate values for $V$ are $<3$, $1.5,1.2, \leqslant 1$, for $W 2.25,3,<2, \leqslant 1$, for $A 2.66,1.25,1.2, \leqslant 1$. On $1 y$ W gives any indication of characteristic short downturn shortly behind level of end of soft dorsa1; the short predorsal rise is recognizable only in $\mathrm{A}$.

(d) Upper jaw. In $V$ the shaft of the maxilla is evident right to the dorsum of the snout, further than it is normally in view, in $W$ the premaxilla is not carried sufficiently far back; in A the hind end of the jaw lacks the characteristic broad expansion and no clear distinction between maxilla and premaxilla is apparent. (e) Opercular angle. The upper border varies from slightly to moderately concave; in A about linear. The lower border presents a small but distinct notch; shown in $\mathrm{V}$ but not in $\mathrm{W}$ or $\mathrm{A}$. (f) Pectoral. In some individuals the upper border is evenly convex as in $W$, in others it presents two subcqual almost straight segments with a well rounded junction as in $V$; junction too acute in $A$. (g) Ventral. The evenly convex distal border is shown slightly concave in ; the sharply pointed form of the fin is not apparent in A. (h) Anal. The origin is correctly depicted in $W$ as being in advance of second dorsal by one or two rays, is somewhat too anterior in $\mathrm{V}$ at middle of interdorsal, is much too advanced in $A$ under first dorsal termination. The termination of the fin lies behind that of the second dorsal by about 4 rays, as in $V$ and $W$; in $A$ too far forward, level with dorsal termination (in text 


\section{E.0.G.Scott}

"originates beneath last rays of first dorsal"). (i) Caudal. The original specification of the caudal of Aphritis umizliz was "coupée carrément"; no specification was provided for Eleginus bursinus. In a good description of a victorian example (as Aphmitis bassi bassi an unjustifiable emendation for bassii), which remains perhaps the best published account of the present species, Ogilby $(1890: 69)$ gives "crescentic". Andrews has "slightly rounded", though his figure shows the fin as emarginate. The modal degree of convexity approximates that indicated in Waite's figure, tending to be less than that in Valenciennes". However, an occasional individual exhibits a distinctly concave border, this being particularly noticeable in Museum material from the Gawler River.

\section{Coloration}

The treatment of coloration in the original description of Aphritis urvizzii is brief; fuller accounts appear in the original description of Castelnau's Pseudaphmitis bassit (which gives an indication of colors in life) and in a redescription of that species by 0gilhy $(1890: 67)$. In offering a new figure Waite (1924) called attention to some de ficiences in Valenciennes' plate, notable the omission of two dark stripes, with cross bars, along the tlank, the absence of dark markings of the upper part of cne peciulas anu las presence of more than three rows of spots in the caudal. He noted also a feature not previous 1 y reported, "spots" [= dashes] on the outsicle of the ventral. No attempt to indicate color pattern on the body is made in Andrew's figure. Descriptions by Castelnau, ogilby and (apparently) by wate each refer to a single individual. Some additional observations, based on the 15 Earthwatch examples, are here made.

The degree of development of the two lateral stripes that are such a characteristic feature of this species (the upper at times tendjng to blend with the general dark region above the lateral line) shows considerable variation, ranging from virtually a complete line to a variably definite series of discomnected units, subcircular, subel1iptical (as in W) , rectangular or linear. The light-colored interspaces between the bars connecting the stripes are commonly more sharply demarcated than as figured, and may take the form of black or blackish bordered rectangles or squares; modal1y 11-12, 2 wholly below pectoral In young individuals the flank below the inferior stripe, yellowish imnaculate in adult, tends to be whiter and less extensive vertically, and to show some, even heavy, stippling. The half dozen indistinct broad dark bars between the lateral line and the dorsal profile shown in $W$ are in some of our examples much darker and more conspicuous, the hindmost being identifiable as the black spot or blotch regularly located at the caudal base. Quite small specimens ( $\mathrm{Ls} \leqslant 60 \mathrm{~mm}$ ) possess 6 conspicuous evenly-spaced black saddles, not previously reported, their anteroposterior extensions subequal to their interspaces, the color extending to a variable degree on to the upper lateral surface, where in most cases it alternates with the dark lateral bars: in adults these tend to become indistinguishable in the general darkening of the whole dorsum.

Head marbled blackish and yellow (sides purple, in front of eyes red, Castelnau). The two black bars running obliquely down and back froin the eyes, first noted by ogilby and shown in $W$ as discontinuous are usually traceable, and may become continuous and sharply defined, though, on the other hand, the upper one may become merged with a general postorbital darkness; a third oblique bar in advance of the eye, just indicated in W, is usually present. Interorbital commonly blackish, upper surface of snout light-dark grey. Lips either mainly dark, greyish or ivory behind, or mainly greyish, blackish behind; at times with some dark spotting or mottling. Ventral surface of snout with variable dark markings laterally; almost invariably some pigmentation along the isthmus, in young as punctuations only, in some larger examples as a sharply demarcated black stripe, its width about one-fourth its length, the latter twice eye. Branchiostegal membrane hyaline; rays off-white, exceptionally with some sparse pigmentation.

Each dorsal spine with 2-4, modally 3 , spaced blackish lines (not spots as in V): All accounts speak of, and all illustrations show, first dorsal membrane as hyaline: in our naterial it regularly exhibits some pigmentation, the most constant feature being a pennon-like series of melanophores in each inter-radial panel, usually in its distal half, sloping down and forward, the broad end superior. Each ray of the soft dorsal presents two moities extending throughout its length, becoming noticeably apart distally; each ramus bears 3-4 spaced patches or, more commonly, lines of dark pigmentation - well shown in w, 
not evident in $V$ or $A$. The membrane, consistently described and figured as immaculate is indeed chiefly so; however, in most individuals there are some areas of pigmentation similar in form and location to those in the first dorsal but in general decidedly less developed with fewer melanophores. Anal as preserved white (pink, Castelnau); as described and figured, characteristically immaculate; rarely with some dark lines on the rays similar to, but less pronounced than, those on the dorsal spines. Almost invariably at least a blackish smudge, in most specimens a conspicuous spot on either side of the base of each anal ray. Pectoral much as in $W$, but the dark lines on the rays more pronounced, increasing in length outward, forming about 7 conspicuous arcs; commonly, as in w, not developed on several inferior rays, making the fin distinctly bicolor; exceptionally all rays may be pigmented, though in the lower ones only distally; a dark patch or patches at base of fin: no markings in $\mathrm{V}$, in $\mathrm{A}$ no distinction between upper and lower rays. Markings on the ventral first noted and figured by wate; these may be as shown or may form recognisable arcs of dark lines or smudges; regularly absent or poorly-developed in young. Waite criticized $V$ as showing caudal with too few arcs of spots (3) and himself indicated about 7 ;

Castelnau "yellow, with four or five transverse crimson bands", Ogilby, somewhat inexplicably, "purple with two transverse white bars on the posterior half". In the preserved West Coast material the white or pale grey rays each with $4-7$ dark grey or blackish spots or lines, tending (a feature not evident in illustrations) to increase dista11y in 1ongitudinal extent.

\section{ACKNOWLEDGEMENI'S}

Material in the Queen Victoria Museum and Art Gallery, Launceston has been made available through the courtesy of the Director, Mr C.B. Tasse11: it includes specimens of Pseudaphritis bursinus and Gasterochisma meZamous collected by a combined EarthwatchMuseum expedition to the west coast of Tasmania in March and April 1981. The writer is deeply indebted to Miss Kaye Dimmack for painstaking preparation of the typescript and preparation of the figures. Thanks are tendered to the staff of the Radiography Department Launceston General Hospital for the radiograph of the Cubiceps and to Mr D.R. Barratt for the preparation of the photoyraph for reproduction; to Mr D.J. Cherry, Editor, Advocate, for the fine photograph of the oarfish; to Mrs M. Marshall, Librarian, Royal Society Library, for ready response to inquiries on literature.

\section{REFERENCES}

Agassiz, L.J.B., 1845: NOMENCLATOR ZOOLOGICA: PISCES.

Ahlstrom, E.H., Butler, J.I., and Sumida, B.Y., 1976: Pelagic stromateoid fishes (Pisces, perciformes) of the eastern Pacific: kinds, distributions, and early life histories and observations on five of these from the northwest Atlantic. BuzZ. Mar. Sei., 26: 285-402.

Aleev, Yu.G., 1977: Stavridy (Trachurus) morei SSSR. Trudy Sevastopol'skoi Biologicheskoi Stantsii, 9: 167-242.

Aliport, M., prior to 1882: MS list of Tasmanian fishes, with reference to the folio of Dr Ginther's Catalogue of fishes.

Andrews, A.P., 1980: Family Bovichthyidae: 167-168, fig.30.1. In McDowall, R.M., (Ed.): FRESHWATER FISHES OF SOUTH-EASTERN AUSTRALIA (NEW SOUTH WALES, VICTORIA AND TASMANIA). A.H. and A.W. Reed, sydney.

Ascanius, 1772: ICONES RERUM NATURAE.

Berg, C., 1895: Enumeración sistematica y sinonimica de los Peces de las Costas Argentina y Uruguaya. An. Mus. Buenos Aires, IV: 1-120, pl.1.

Berry, F.H. and Cohen, L., 1974: Synopsis of the species of Trachums. Quart. J. Flomida Acad. Sci., 35: 177-211.

Bleeker, P., 1853: Vemh. Bat. Gen., 25, 1853, Muraen: 9, 28.

Boulenger, G.A., 1910: Fishes (systematic account of Teleostei). In CAMBRIDGE NATURAL HISTORY, 7. MCMilian, London.

Butler, J.L., 1979: The nomeid genus Cubiceps (Pisces) with a description of a new species. Bulz. Mar. Sei., 29(2): 226-24l, figs 1-11.

Castelnau, F.N., 1872: Contribution to the ichthyology of Australia. No.I. The Melbourne Fish Market. Proc. zool. acclim. Soc. Vict., 29-242, one pl. 
Craddock, J.E. and Mead, G.W., 1970: Midwater fishes from the eastern South Pacific Ocean. Sei. res. Southeast Pac. Erped. "Anton Briun", 3.

Cuviex, G.L.C.D.F., 1830: In Cuvier, G. and Valenciennes, A., HISTOIRE NATURELLE DES POISSONS, 5 . POISSONS, 9 .

De Vis C.W., 1891: Note on Regalecus masteri. Proc. R. Soc. Q2d, 7: 13- Momen nudum. 1892: The ribbon fish (A Regalecus in queensland waters). Proc. R. Soe. Q2], 8: 109-113.

Forbes, H.O., 189.1: On a species of Regalecus or great oar-fish, caught in okain's Bay. Trans. N.Z. Inst., 24: 192

Goode, G.B. and Bean, T.H., 1895: oceanic ichthyology. Spec. BuzZ. U.S. Nat. Mus., 25 : 1-529, pls 1-123.

Greenwood, P.H., Rosen, D.L., weitzman, S.H. and Myers, G.S., 1966: Phyletic studies of teleostean fishes with a provisional classification of living forms. BuZL. U.S. Mus. Nat. Hist., I3I (4).

Griffin, L.T., 1932: A revision of the carangid and seriolid fishes of New Zealand. Rec. Auckt. Mus., $1(3): 123-134$.

Günther, A., 1861: CATALOGUE OF THE ACANTHOPTERYGIAN FISHES IN THE BRITISH MUSEUM, 3. British Museum, London.

, 1874: Zoological Recora (1871).

, 1880: AN INTRODUCTION TO THE STUDY OF FISHES. A. \& C. Black, Edinburgh.

, 1889: Report on the pelagic fishes collected by H.M.S. Challenger, during the years 1873-1876. Rept Sei, res. Challenger, 31(78): 1-47, pis $1-6$.

Haast, J. von, 1877: Trans. N.Z. Inst., 9: 646. Nomen nudum.

, 1878: Notes on Regalecus pacificus, a new species of ribbon fish from the

New Zealand seas. Trans. N.Z. Inst., 10:246-250, pl.7.

Haedrich, R.L., 1967: The stromateoid fishes: systematics and classification. Bul2. Mus. Comp. Zoot. Harvard, $115(2) ; 31-39,56$ figs.

, 1972: Ergenisse der Forschungreisen des FFS 'Walter Herwig' nach Sudamerika, 23: Fishes of the family Nomeidae (Perciformes, Stromatoidei). Arch. Fischereiwiss., 23: 73-88.

Hale, H.M., 1920: (Observations on Pseudaphritis urvizzii.) Aquatic Life, 5.

Hector, J.J., 1870: On a species of Ophisurus found on the coast of New Zealand, with anatomical observations by F.J. Knox. Trans. N.2. Inst., 2: 34-40, pl.3.

Hoese, D.F., 1976: Family Nomeidae. In Annotated Checklist of the fishes of Lord Howe Island; G.R. Allen, D.F. Hoese, J.R. Paxton, J.E. Randall, B.C. Russell, W.A. Starch II, F.H. Talbot and G.P. Whitley. Rec. Aust. Mus., 30 (15): 365-454.

Hutton, F.W., 1896: Notes on some New Zealand fishes, with description of a new species. Trans. N.Z. Inst., 28: 314-318.

Johnston, R.M., 1883: General and critical observations on the fishes of Tasmania; with. a classified catalogue of all known species. Pap. Proc. R. Soc. Tasm. (1882): 54-144. , 1891: Further observations on the fishes and fishing industries of Tasmania, together with a revised list of the indigenous species. Pap. Proc. R. Soc. Tasm. (1890): $22-46$.

Karrer, C., 1975: Uber fische aus dem Sudostatlantik, 2. Mitt. Zool. Mus. Berlin, 51(1), $63-82$.

Lacépède, B., 1880: HISTOIRE NATURELLE DES POISSONS, 2. Plassen, Paris.

Last, P.R. and Harris, J.G.K., 1981: New locality records and preliminary information on demersal faunal assemblages in Tasmanian waters. Pap. Proc. R. Soc. Tasm., 115: 189209.

Linné, C. von, 1758: SYSTEMA NATURAE, ed.10. Holmiae.

Lord, C.E., 1923: A list of the fishes of Tasmania. Pap. Proc. R. Soc. Tasm. (1922): 6073 .

, 1927: A list of the fishes of Tasmania. J. Pan-Pac. res. Inst., 2(4): 11-16. and scott, H.H., 1924: A SYNOPSIS OF THE VERTEBRATE ANIMALS OF TASMANIA. Oldham, Beddome and Meredith, Hobart.

Lowe, R.T., 1843: Notices of fishes newly observed or discovered in Madeira, during the years 1840, 1841 and 1842. Proc. Zool. Soc. London, 11: 81-95.

Lucas, A.H.S., 1890: A systematic census of indigenous fishes hitherto reported from Victoria. Proc. R. Soc. Viet. (n.s.), 2: 15-47. 
M'COY, F, 1878: PRODROMUS OF THE ZOOLOGY OF VICTORIA, 2. Govermment Printer, Melbourne. 1887: Ibia., 15 .

McCulloch, A.R., 1915: Report on some fishes obtained by the F.I.S. "Endeavour" on the coasts of queensland, New South wales, Victoria, Tasmania, South and southwestern Australia. Biol. res. "Endeavour", 3(3): 169-199, pls 44-57, figs 1,2.

, 1921: Check-list of the Ejsh and fish-like animals of New south wales. Part 2. Aust. Zool., 2(2): 14-68, pls 4-24. , 1922: Check-list of the fish and fish-like animals of New south wales. Part 3. Aust. Zool., 2(3): 86-130, pls 25-43.

, 1923: Notes on fishes from Australia and Lord Howe Island. Rec. Aust. Mus., 14(1): 15: 1-17, pls 1.-3.

, 1927: THE FISHES AND FISH-LIKE ANIMALS OF NEW SOUTH WALES. 2nd ed., with additions by G.P. Whitley. Royal zoological Society of New south wales, syaney. , 1929: A check-list of the fishes recorded from Australia. Aust. Mus. Mem., 5(1-4) (part 4, Index, 1930).

MCDOWall, R.M. (Ed.), 1980: FRESHWATER FISHFS OF SOUTH-EASTERN AUSTRALIA (NEW SOUTH WALES, VICTORIA'AND TASMANIA). A.H. \& A.W. Reed, Sydney.

Macleay, W., 1881: Descriptive catalogue of the fishes of Australia. Part 2. Proc. Linn. Soc. N.S.W., 5(4): 510-629.

, 1882a: Descriptive catalogue of Australian fishes. Part 3. Proc. Linn. SOC.N.S.W., $6(1): 1-138$.

, 1882b: Descriptive catalogue of Australian fishes, part 4. Proc. Iirm. Soc. N.S.W., $6(2): 202-387$.

Marshall, T.C., 1964: FISHES OF THE GREAT BARRIER REEF AND THE COASTAL WATERS OE QUEENSLAND. Angus \& Robertson, Syaney. Sydney. ' 1966: TROPICAL FISHES OF THE GREAT BARRIER REEF. Angus \& Robertson,

Munro, I.S.R., 1957a: Handbook of Australian fishes, 11: 45-48, figs 315-345. In Fisher. Newst. (now Aust. Fisher.), $16(5)$. , 1957b: Ibia., 15: 61-64, figs 431-453. In Ibid., 16(9). , 1958a: Ibid., 27: 109-112, figs 733-752. In Ibid., 17 (9). , 1958b: Ibid., 29: 117-120, figs 774-793. In Ibid., $17(11)$. , 1958c: Ibia., 30: 121-124, figs 794-812. In Ibid., 17(12).

Nelson, J.S., 1978: Limichthys polyactis, a new species of blennioid fish from New Zealand, with a note on the taxonomy and distribution of other Creediidae (including Limnichthyidae). N.Z. J. Zool., 5: 351-364, figs 1-5.

Nichols, J.T., 1920: A key to the species of Trachurus. Bul2. Amer. Mus. Nat. Hist., 42. Ogilby, D.G., 1890: Redescription of Pseudaphritis bassi, Castelnau. Rec. Aust. Mus., $1(3): 55-56$.

, 1897a: Some Tasmanian fishes. Pap. Froc. R. Soc. Tasm. (1896): 69-85. , 1897b: On a larval teleost from New South wales. Proc. Linn. Soc. N.S.W., $22(1)=158-160$, fig.l.

, 1898: Note on the genus Aphritis, C. \& V. Proc. Linn. Soc. N.S.W. (1897): $22(3): 554-560$.

Parker, T.J., 1883: On a specimen of the great ribbon fish (Regalecus argenteus, n. sp.), recently obtained at Moeraki, Otago. N.Z. J. Sci., 1: 520 .

, 1884: On a specimen of the great ribbon fish (Regalecus argenteus, n. sp.), lately obtained at Moeraki, Otago. Trans. N.Z. Inst. (1883): 16: 284-296, pls 23,24. 1888: On a specimen of Regalecus stranded in otago Harbour. Trans. N.Z. Inst., 20: 20-29, pl.5.

Pequeno, R.G., 1976: The nomeid fish Cubiceps capensis in the south Pacific Ocean. Copeia, 1976: 805-806.

phillipps, W.J., 1924: Agrostichthys, a new genus of Ribbon fishes. Proc. Zoot. Soc. London, $11(2): 539-540$, figs 1,2 .

Rafinesque, C., 1810: CARATTERI DI ALCUMI NUOVI GENERI E NUOVI SPECIE DI ANIMALI E PLANTE DELLA SICILIA. Palermo.

Regan, C.T., 1914a: BRITISH ANTARCTIC ("TERRA NOVA") EXPEDITION, ZOOL., 1, FISHES: 1-54. - 1914b: Diagnosis of new marine fishes collected by the British Antarctic ("Terrá Nova") Expedition. Am. Mag. Nat. Hist., ser.8, 13: 11-17.

Richardson, J., 1843a: Report of the British Association for the Advancement of Science: 12 th meeting (1842): 21 . 
Richardson, J., 1843b: In TRAVELS IN NEW ZEALAND (Diffenbach): 210.

- 1845: Generic characters of Gasterochisma metampus, a fish which inhabits Port Nicholson, New Zealand. Ann. Mag. Nat. Hist., 15: 346.

Schlegel, H., 1850: In Temminck, C.J. and Schlegel, H, FAUNA JAFONICA.

Schultz, I.P., 1953: Family ophichthidae: 45-60, figs 10-12. In schultz et al., Eishes

of the Marshall and Marianas Islands, i (Asymetrontidae through Siganidae). U.S. Nat. Mus. Bull., 202 .

Scott, E.0.G., 1934-1981: Observations on some Tasmanian fishes. Parts I-XXVII in this journal (except Part XVI, 1969, Aust. Zool., 15(2): 160-177, figs 1,2). Contributions here cited. 1953 (1952), VI: 141-166, figs 1-4. 1957, VIII: 145-156. 1960, IX: 87-101, fig.1. 1963, XI: 1-31, figs 1-8, 1974, XIX: 249-292, figs 1,21. 1978, XXIV: 289-356, figs 1-3. 1979, XXV: 99-148. 1980, XXVI: 85-144, pls 1,2, text figs 1,2. 1981, XXVII: 101-152, pl.1, text fig.l.

, 1982: Notes on fishes in the collection of the Queen Victoria Museum, Launceston. Part 1. Reo. Queen Vict. Mus., 74.

Scott, T.D., 1962: THE MARINE AND FRESH WATER FISHES OF SOUTH AUSTRAITA. GOVENMMULL Printer, Adelaide.

, Glover, C.J.M. and Southcott, R.V., 1974: THE MARINE AND FRESHWATER FISHES

OF SOUTH AUSTRALIA. Government Printer, Adelaide.

Smith, A., 1840: ILLÜSTRATED ZOOLOGY OF SOUTH AFRICA. PISCES.

Stephenson, A.B. and Robertson, D.A., 1977: The New Zealand species of Trachumus (Pisces: Carangidae). J. R. Soc. N.Z., 7(2): 243-253. figs 1-3.

Suzuki, K., 1962: Anatomical and taxonomic studies on the carangid fishes of Japan. Rept Faculty Fisher. Prefectural Univ. of Mie, 4(2): 43-230.

Temminck, C.J. and Schlegel, H., 1844: Pisces, Part 3. In Siebold, P.H. von, FAUNA JAPONICA. Leiden.

Valenciennes, A., 1831: In Cuvier, G. and Valenciennes, A, HISTOIRE NATURELLE DES POISSONS, 8 .

Waite, E.R., 1904a: Additions to the fauna of Lord Howe Island. Rec. Aust. Mus., 5(3): $135-186$. $187-230$.

, 1904b: Catalogue of the fishes of Lord Howe Island. Rec. Aust. Mus., 5(3):

1910: A list of the known fishes of Kermadec and Norfolk Islands, and a comparison with those of Lord Howe Island. Trans. N.Z. Inst., 42: 370-383.

, 1912: Notes on New Zealand fishes. No.3, Proc. N.Z. Inst., 45: 215-224 pls 5-9.

1921: Illustrated catalogue of the fishes of South Australia. Rec. S. Aust.

Mis., 2(l): 1-208, pl.1, 332 figs.

, 1923: THE FISHES OF SOUTH AUSTRALIA. Government Printer, Adelaide.

, 1924: Illustrations of and notes on some Australian fishes. Rec. S. Aust.

Mus., 2(4): 480-487, pls 29-31, figs 379,380 .

Wakiya, Y., 1924: The carangoid fishes of Japan. Ann. Carmegie Mus. Pittsb., 15: 139-244. Whitley, G.P., 1929: R.M. Johnston's memoranda on the fishes of Tasmania. Pap. Proc. R. Soc. Tasm. (1928): 44-68, pls 2-4l.

, 1933: Studies in ichthyology. No.7. Rec. Aust. Mus., 19(1): 60-112,

pls 11-15, figs 1-4.

, 1948: A list of the fishes of western Australia. W.A. Fisher. Dept Bulz.,

$2: 1-35, \operatorname{map}$.

1962: MARINE FISHES OF AUSTRALIA, 2. Jacaranda Press, Brisbane.

1964: Name-list of the fishes recorded from Australia. Presidential

address, appendix B. Proc. Linn. Soc. N.S.W., 89(1): 32-60 (list), 11-127 (address) , 1968: A check-list of the fishes recorded from New Zealand. Aust. Zool.,

$15(1): 1-102$, figs 1,2 . 